\title{
Transverse Distribution of the Streamwise Velocity for the Open-channel Flow With Floating Vegetated Islands
}

Xuecheng Fu

Wuhan University

Feifei Wang

Wuhan University

Mengyang Liu

Wuhan University

Wenxin Huai ( $\square$ wxhuai@whu.edu.cn )

wuhan university

\section{Research Article}

Keywords: Floating vegetated island, Depth-averaged streamwise velocity, Velocity distribution, Secondary flow, Comprehensive friction factor, Drag force term

Posted Date: February 8th, 2021

DOI: https://doi.org/10.21203/rs.3.rs-165125/v1

License: (9) This work is licensed under a Creative Commons Attribution 4.0 International License. Read Full License 


\title{
Transverse distribution of the streamwise velocity for the open- channel flow with floating vegetated islands
}

\author{
Xuecheng Fu ${ }^{1}$, Feifei Wang ${ }^{1}$, Mengyang Liu ${ }^{1}$, Wenxin Huai ${ }^{1, *}$ \\ ${ }^{1}$ State Key Laboratory of Water Resources and Hydropower Engineering Science, Wuhan University, \\ Wuhan, Hubei 430072, China
}

\section{E-mail Addresses:}

Xuecheng Fu, xuechengfu@whu.edu.cn;

Feifei Wang, ffwang1991@whu.edu.cn;

Mengyang Liu, liumy@whu.edu.cn;

Wenxin Huai, *Corresponding author, wxhuai@whu.edu.cn.

\section{Abstract}

Floating vegetation islands (FVIs) have been widely utilized in various river ecological restoration projects due to their ability to purify pollutants. FVIs float at the surface of shallow pools with their roots unanchored in the sediment. Biofilm formed by roots under islands filters nutrients and particles in the water flowing through it. Flow field disturbance will occur and transverse distribution of flow velocity will change due to the existence of FVIs. Transport efficiency of suspended solids, nutrients, and pollutants will also be altered. A modified analytical model that considers effects of boundary friction, drag force of vegetation, transverse shear turbulence, and secondary flow is established to predict transverse variation of depth-averaged streamwise velocity for the open-channel flow with FVIs using Shiono and Knight method. The simulation results with suitable boundary conditions successfully predicted lateral profile of the depth-averaged streamwise velocity compared with the experimental results of symmetrical and unsymmetrical arrangements of FVIs. Hence, the presented model can provide guidance for investigating flow characteristics of rivers with FVIs.

Keywords: Floating vegetated island · Depth-averaged streamwise velocity · Velocity distribution $\cdot$ Secondary flow $\cdot$ Comprehensive friction factor $\cdot$ Drag force term

\section{Highlights}



vegetated islands is proposed.

The modeled results indicate good predictions in depth-averaged streamwise velocity.

The new calculation method of comprehensive friction factor is derived.

Introduction

Floating vegetation islands (FVIs) are widely used in river ecosystem recovery projects due to their satisfactory pollutant purification ability. Roots of floating macrophytes on the surface of shallow pools are unanchored in the sediment (Nahlik and Mitsch 2006; Downing-Kunz and Stacey 2011). The root system extends down to the river bottom and provides for the matrix in the formation of biofilm with its ability to remove small suspended particles, dissolved pollutants, and nutrients (Billore and Sharma 2009; Hwang and LePage 2011; Tanner and Headley 2011; Chua et al. 2012; Liu et al. 2019). The existence of FVIs remarkably alters the internal structure of fluid, increases the complexity of the flow pattern (Yang et al. 2007), and impacts the transport and diffusion of pollutants and sediment transfer (Huai and Li 2016). Specifically, FVIs directly affect the surface of the fluid by reducing the flow velocity in this area. The vertical distribution of the streamwise velocity is altered and the maximum velocity appears in the middle water depth rather than the water surface under the joint action of FVIs and rough flume bed unlike the open-channel flow. However, flow characteristics of the open-channel flow with FVIs are similar to those of ice-covered channels. Therefore, investigating flow characteristics of the open-channel flow with FVIs, such as velocity distribution, flow rate, and secondary currents, is necessary.

The depth-averaged streamwise velocity of natural streams should be predicted first to explore the sediment transport and river evolution (Bonakdari 2012; Liu et al. 2013a), and the total rate of flow can then be obtained by integrating the depth-averaged streamwise velocity over the cross section. The transverse distribution of the streamwise velocity in the open channel with FVIs can be acquired according to the depth-averaged Navier-Stokes (N-S) equation. Shiono and Knight (1991) initially derived the depth-averaged form of the $\mathrm{N}-\mathrm{S}$ equation in the compound channel. The majority of studies on the transverse distribution of the streamwise velocity in the channel have focused on the flow through submerged and 
emergent canopies, typically introduced the term of vegetation drag force into the $\mathrm{N}-\mathrm{S}$ equation while considering the effect of the canopy, and applied different methods to improve the model. For instance, Chen (2010) and Huai (2011) derived a nondimensional form of the $\mathrm{N}-\mathrm{S}$ equation to overcome limitations caused by the dimensional one and quantify the effects of gravity and friction. A certain number of subregions in the transverse direction were defined with different parameters in each subregion on the basis of mixing layer theory (White and Nepf 2008; Huai et al. 2013; Liu et al. 2013b; Fernandes et al. 2014). Modified calculation methods of unknown coefficients, such as friction, eddy viscosity, and secondary flow coefficients, are put forward to improve the reliability of the calculation results (Rameshwaran and Shiono 2007; Huai et al. 2008; Huai et al. 2009; Devi and Khatua 2016). Meanwhile, some studies have focused on the ice-covered channel flow because its flow characteristics are similar to those of the channel flow with FVIs to some extent. Zhong (2019) and Wang (2020) investigated the transverse distribution of the depth-averaged streamwise velocity in the rectangular flume and the compound channel according to a twolayer hypothesis, respectively. However, studies concentrating on the transverse distribution of the depth-averaged streamwise velocity of the open-channel flow with FVIs are limited.

Accordingly, an analytical model derived from the Shiono and Knight method (SKM) (Shiono and Knight 1991) and secondary flow theory (Ervine et al. 2000) for predicting the transverse distribution of the depth-averaged streamwise velocity in the open channel with FVIs is proposed in this study. Canopy resistance is added to the $\mathrm{N}-\mathrm{S}$ equation that considers the existence of FVIs, and the analytical solution of the depth-averaged streamwise velocity is obtained by solving the governing equation. The analytical solution is then compared with experimental data acquired from symmetrical and unsymmetrical arrangements of FVIs. The consistency of the modeled results with experimental data proves the reasonability and validity of the analytical model. Meanwhile, the analytical model can provide a reference for investigating flow characteristics of the open channel with FVIs.

\section{Experimental setup}

Two experimental conditions, namely, symmetrical and asymmetrical arrangements of FVIs, are carried out in the laboratory, as illustrated in Fig. 1, and their corresponding series of cases are illustrated in Fig. 2. Specifically, the experiment was conducted in a $20 \mathrm{~m}$ long and $1 \mathrm{~m}$-wide $(B)$ glass flume with a bed slope $S_{0}$ equal to $0.01 \%$. FVIs with widths of 0.6 and $0.3 \mathrm{~m}(b)$ are arranged symmetrically along the center with lengths of 5 and $8 \mathrm{~m}$, respectively, while its unsymmetrical counterpart with a respective width and length of $0.3(b)$ 
and $8 \mathrm{~m}$ is set close to the shore wall. Moreover, steady and uniform flow is adopted in these cases. The water depth is adjusted using a tailgate with the discharge regulated by an electromagnetic flowmeter installed upstream of the channel, and the point velocity is measured with a SonTek 3D Acoustic Doppler Velocimeter (ADV). The root system of

97 floating vegetation is simulated using a series of rigid columns. Columns are orthogonally aligned with the side length of the square element equal to $0.05 \mathrm{~m}$. The canopy height and diameter are $h_{c}=0.25 \mathrm{~m}$ and $D=0.006 \mathrm{~m}$, respectively. Columns are vertically attached to several suspended polyvinyl chloride (PVC) plates. The channel bed is covered with some 2 m-long, $1 \mathrm{~m}$-wide, and $0.01 \mathrm{~m}$-thick PVC base plates.

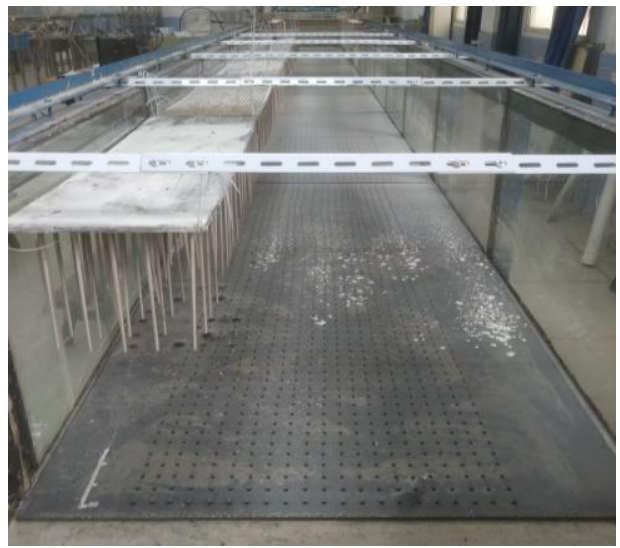

(a) Asymmetrical arrangement case

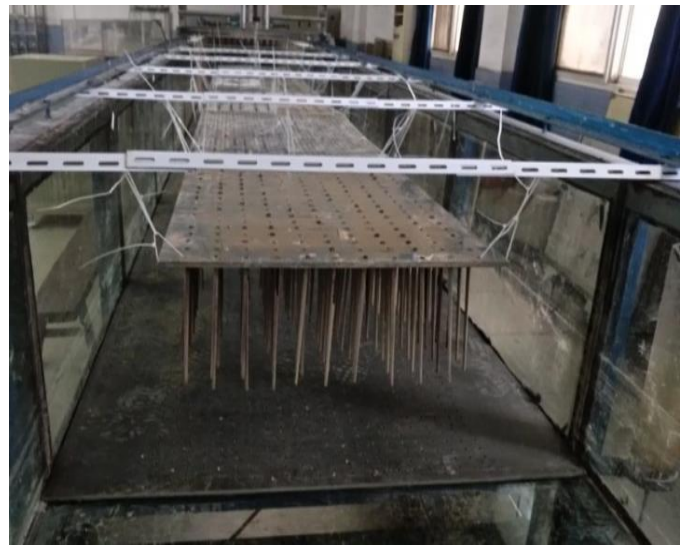

(b) Symmetrical arrangement case

Fig. 1 Global view of the channel with different FVI arrangements 
(a)

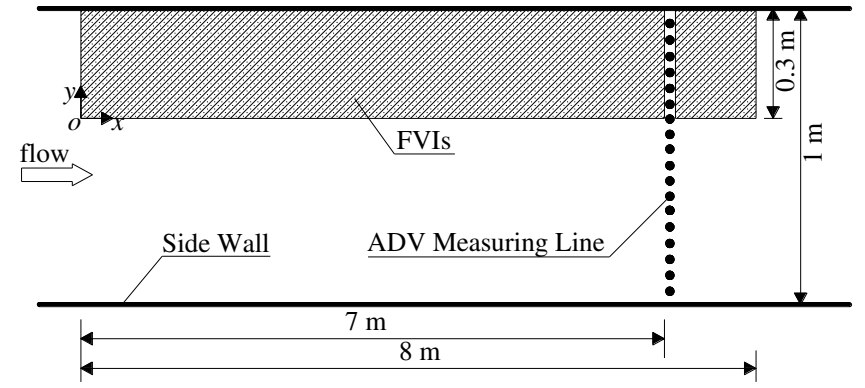

(c)

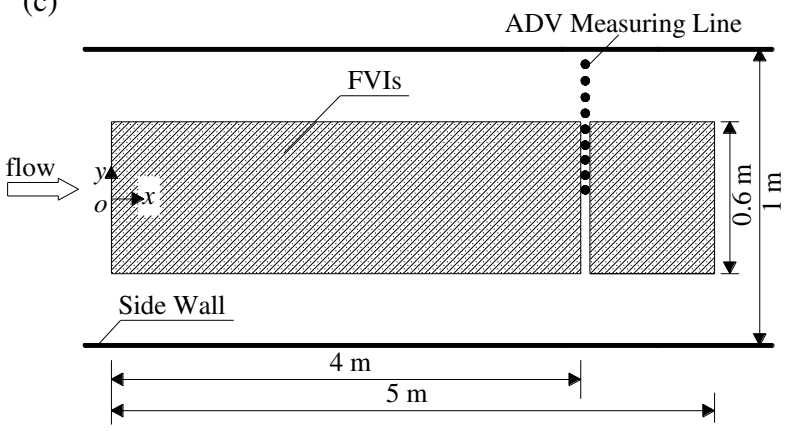

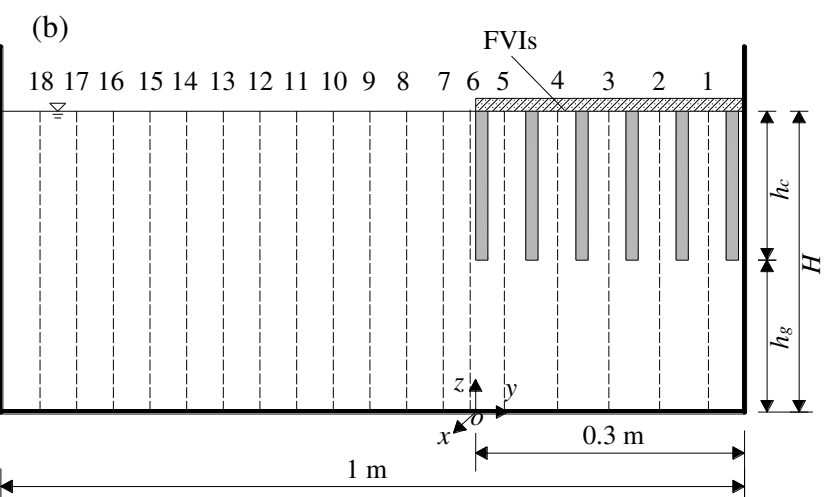

(d) Center Line FVIs

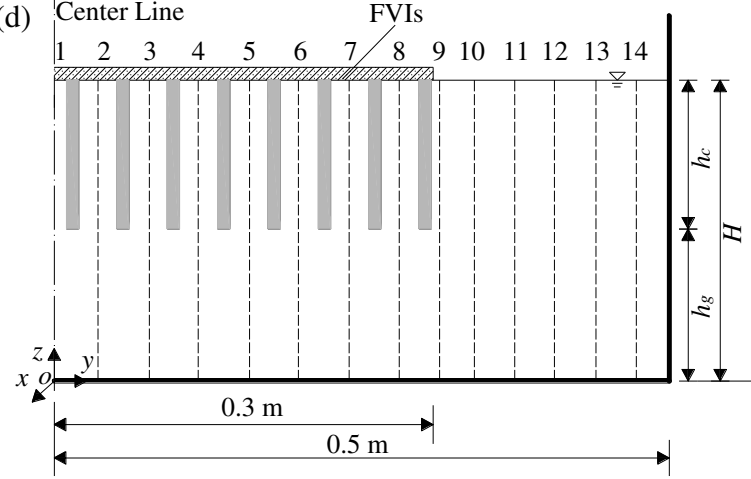

Fig. 2 Diagrams of the FVI layout in the laboratory flume: (a) Top view of the asymmetrical arrangement case; (b) Cross-section profile of the asymmetrical arrangement case; (c) Top view of the symmetrical arrangement case; (d) Cross-section profile of the symmetrical arrangement case with the canopy height $h_{c}$, gap height $h_{g}$, and water depth $H$

The entire cross section of the unsymmetrical arrangement of FVIs is considered for analysis, while half of the channel is analyzed for symmetrical case on account of its symmetry. Fig. 2 shows the diagrams of unsymmetrical and symmetrical cases, including top views and cross-sectional drawings. The measuring section is set $1 \mathrm{~m}$ away from the end of FVIs. Fourteen to eighteen measuring lines are taken in the cross-sectional direction according to different arrangement cases. Seventeen to twenty-two measuring points are selected for each perpendicular with a measuring spacing of $0.02-0.04 \mathrm{~m}$ to improve the accuracy of the vertical velocity distribution. Instantaneous velocities are obtained using the $\mathrm{ADV}$ at a frequency of $50 \mathrm{~Hz}$ with a sampling period of $160 \mathrm{~s}$. High-quality measuring data are then conserved by removing low signal-to-noise ratio $(<15 \mathrm{~dB})$ and low-correlation $(<70 \%)$ samples. Water depths of 0.43 and $0.48 \mathrm{~m}$ are adopted under these working conditions. Experimental parameters are listed in Table 1.

\section{Table 1}

Geometric and hydraulic parameters of experiments 


\begin{tabular}{lcccccccc}
\hline Cases & FVI layout & $Q\left(\mathrm{~m}^{3} / \mathrm{s}\right)$ & $H(\mathrm{~m})$ & $h_{c}(\mathrm{~m})$ & $h_{g}(\mathrm{~m})$ & $b(\mathrm{~m})$ & $B(\mathrm{~m})$ & $S_{0}(\%)$ \\
\hline Run 1 & Symmetric arrangement & 0.0420 & 0.43 & 0.25 & 0.18 & 0.6 & 1.0 & 0.01 \\
Run 2 & Symmetric arrangement & 0.0469 & 0.48 & 0.25 & 0.23 & 0.6 & 1.0 & 0.01 \\
Run 3 & Symmetric arrangement & 0.0423 & 0.43 & 0.25 & 0.18 & 0.3 & 1.0 & 0.01 \\
Run 4 & Symmetric arrangement & 0.0475 & 0.48 & 0.25 & 0.23 & 0.3 & 1.0 & 0.01 \\
Run 5 & Asymmetric arrangement & 0.0424 & 0.43 & 0.25 & 0.18 & 0.3 & 1.0 & 0.01 \\
Run 6 & Asymmetric arrangement & 0.0477 & 0.48 & 0.25 & 0.23 & 0.3 & 1.0 & 0.01 \\
\hline
\end{tabular}

$138 \quad F_{v}=\frac{1}{2} \rho\left(C_{d} \beta A_{v}\right) U^{2}$,

\section{Theoretical analysis}

Deriving the depth-averaged streamwise momentum equation with additional canopy resistance is necessary to predict the transverse variation of the depth-averaged streamwise velocity of the open-channel flow with FVIs. By introducing the canopy resistance into the Navier-Stokes equation and combining it with the continuity equation, the governing equation can be obtained as follows (Shiono and Knight 1991):

$\rho\left[\frac{\partial U V}{\partial y}+\frac{\partial U W}{\partial z}\right]=\rho g S_{0}+\frac{\partial \tau_{y x}}{\partial y}+\frac{\partial \tau_{z x}}{\partial z}-F_{v}$,

where $x, y$, and $z$ represent streamwise, transverse, and vertical coordinates, respectively; $U$, $V$, and $W$ are time-averaged velocities in $\{x, y, z\}$ directions; $\rho$ denotes the water density; $S_{0}$ is the channel bed slope; $g$ represents the gravitational acceleration; $\tau_{z x}$ and $\tau_{y x}$ denote the Reynolds shear stresses on planes perpendicular to $z$ and $y$ directions, respectively, $\tau_{z x}=-\rho \overline{u^{\prime} w^{\prime}}$ and $\tau_{y x}=-\rho \overline{u^{\prime} v^{\prime}} ; u^{\prime}, v^{\prime}$, and $w^{\prime}$ are fluctuating velocities in $\{x, y, z\}$ directions. The overbar indicates that parameters are averaged over time. $F_{v}$ is the drag force generated by the canopy per unit fluid volume, which can be expressed as

where $C_{d}$ denotes the vegetation drag coefficient; $\beta$ represents the shape factor of the canopy; 140 and $A_{v}$ is the projected area of canopy per unit volume in the longitudinal direction, $A_{v}=m D$ $141=2.4 \mathrm{~m}^{-1}$ and $m$ represents the number of columns per bed area (Nepf and Vivoni 2000). 


$$
\frac{U_{d_{c}}}{U_{d}}=\frac{-\alpha^{2}-C_{b} h^{2}+(1-h) \sqrt{A h(1-h)\left(C_{b} h+\alpha^{2}\right)-\alpha^{2} C_{b} h}}{A h(1-h)^{3}-\alpha^{2}-C_{b} h^{3}}=P_{u},
$$
water depth $H$. Assuming that $W(0)=W(H)=0$, we have

$\rho \frac{\partial H(U V)_{d}}{\partial y}=\rho g H S_{0}+\frac{\partial H \bar{\tau}_{y x}}{\partial y}-\tau_{d}-\int_{0}^{H} \frac{1}{2} \rho\left(C_{d} \beta A_{v}\right) U^{2} d z$ resistance term can be expressed as

$\int_{0}^{H} \frac{1}{2} \rho\left(C_{d} \beta A_{v}\right) U^{2} d z=\int_{h_{g}}^{H} \frac{1}{2} \rho\left(C_{d} \beta A_{v}\right) U^{2} d z=\frac{1}{2} \rho\left(C_{d} \beta A_{v}\right) h_{c} U_{d_{c}}^{2}$, expressed as follows: then averaged vertically.

Eqs. (4) and (5) are substituted into Eq. (3) to obtain the following:

where $(U V)_{d}=\frac{1}{H} \int_{0}^{H} U V d z ; \bar{\tau}_{y x}$ denotes the depth-averaged Reynolds shear stress on the plane perpendicular to the $y$-direction, $\bar{\tau}_{y x}=\frac{1}{H} \int_{0}^{H}\left(-\rho \overline{u^{\prime} v^{\prime}}\right) d z$; and $\tau_{d}$ represents the comprehensive boundary shear stress, $\tau_{d}=-\int_{0}^{H} \frac{\partial \tau_{z x}}{\partial z} d z$. The integral of the canopy resistance term over the water depth $H$ can be divided into two parts, namely, $0-h_{g}$ and $h_{g}-H$. Assuming that the canopy resistance term in the $0-h_{g}$ region is equal to zero, the integral of the canopy

where $h_{g}$ is the height of the gap region; $h_{c}$ is the height of the canopy region, $h_{c}=H-h_{g}$; and $U_{d_{c}}$ is the depth-averaged streamwise velocity in the canopy region, $U_{d_{c}}=\frac{1}{h_{c}} \int_{h_{g}}^{H} U d z$. The relationship between the depth-averaged streamwise velocity in the canopy region and the depth-averaged streamwise velocity of the total water depth $H$ presented in Plew (2011) is

where $U_{d}$ is the depth-averaged streamwise velocity, $U_{d}=\frac{1}{H} \int_{0}^{H} U d z ; h=h_{c} / H ; \alpha$ is a dimensionless parameter, $\alpha^{2}=\left\langle u^{\prime} w^{\prime}\right\rangle_{c} /\left(U_{d_{g}}-U_{d_{c}}\right)^{2} ; U_{d_{g}}$ is the depth-averaged streamwise velocity in the gap region, $U_{d_{g}}=\frac{1}{h_{g}} \int_{0}^{h_{g}} U d z ;\left\langle u^{\prime} w^{\prime}\right\rangle_{c}$ is the shear stress at the bottom of the canopy; $C_{b}$ is the bed friction coefficient; and $A=\overline{C_{d} A_{v}} H / 2$, and the overbar of $\overline{C_{d} A_{v}}$ shows that the vegetation drag coefficient and projected area of vegetation are multiplied and 
$165 \rho \frac{\partial H(U V)_{d}}{\partial y}=\rho g H S_{0}+\frac{\partial H \bar{\tau}_{y x}}{\partial y}-\tau_{d}-\frac{1}{2} \rho\left(C_{d} \beta A_{v}\right) h_{c} P_{u}^{2} U_{d}^{2}$,

166

167

$168 \bar{\tau}_{y x}=\rho \bar{\varepsilon}_{y x} \frac{\partial U_{d}}{\partial y}$

The eddy viscosity method is widely used in numerical simulation. Hence, $\bar{\tau}_{y x}$ can be expressed as follows (Shiono and Knight 1991):

where $\bar{\varepsilon}_{y x}$ denotes the depth-averaged eddy viscosity, $\bar{\varepsilon}_{y x}=\lambda H U_{*} ; \lambda$ represents the

170 dimensionless eddy viscosity; and $U_{*}$ denotes the local shear velocity, $U_{*}=\sqrt{\tau_{d} / \rho}=\sqrt{\frac{f_{d}}{8}} U_{d}$.

Hence, the comprehensive boundary shear stress $\tau_{d}$ can be expressed as

$\tau_{d}=\rho \frac{f_{d}}{8} U_{d}^{2}$

where $f_{d}$ represents the Darcy-Weisbach comprehensive friction factor.

Eq. (6) can only be solved numerically due to the influence of the secondary flow term $\rho \frac{\partial H(U V)_{d}}{\partial y}$ (Rameshwaran and Shiono 2007). Some methods for simplifying the equation have been proposed to solve the equation analytically. The secondary flow term was ignored in Shiono and Knight (1989) to obtain analytical solutions but considered in many other instances, especially in compound channels (Ervine et al. 2000). The secondary flow is assumed to be the constant $\frac{\partial\left[H(U V)_{d}\right]}{\partial y}=\Gamma$ in Shiono and Knight (1991) and determined on the basis of experimental data in particular situations. Ervine et al. (2000) proposed $U=K_{1} U_{d}$ and $V=K_{2} U_{d}$; thus, $U V=K_{1} K_{2} U_{d}^{2}=K U_{d}^{2}$, while $K$ was not considered as a constant in vertical directions (Yang et al. 2007). We adopted the approach in Liu et al. (2013b) to obtain $(U V)_{d}=\bar{K} U_{d}^{2}$. Therefore, the secondary flow term is expressed as follows:

$\rho \frac{\partial H(U V)_{d}}{\partial y}=\rho \frac{\partial\left(H \bar{K} U_{d}^{2}\right)}{\partial y}$

where $\bar{K}$ is the depth-averaged secondary flow coefficient that varies with the roughness and 
dimensional mixing process consisting of a horizontal shear layer and the exchange of mass, energy, and momentum between vegetated and non-vegetated areas (Ervine et al. 2000).

Therefore, Eq. (1) is expressed as

$$
\rho g H S_{0}+\frac{\partial}{\partial y}\left[\rho\left(\frac{f_{d}}{8}\right)^{1 / 2} \lambda H^{2} U_{d} \frac{\partial U_{d}}{\partial y}\right]-\rho \frac{f_{d}}{8} U_{d}^{2}-\frac{1}{2} \rho\left(C_{d} \beta A_{v}\right) h_{c} P_{u}^{2} U_{d}^{2}=\rho \frac{\partial\left(H \bar{K} U_{d}^{2}\right)}{\partial y}
$$

The blocking effect of the canopy, which is represented by the porosity $\delta$, should be considered in addition to the drag force of the canopy. The porosity is related to the volume density of the canopy. The effect of porosity should be considered for all terms, except the drag force term. Thus, Eq. (10) can be rewritten as

$$
\delta \rho g H S_{0}+\delta \frac{\partial}{\partial y}\left[\rho\left(\frac{f_{d}}{8}\right)^{1 / 2} \lambda H^{2} U_{d} \frac{\partial U_{d}}{\partial y}\right]-\delta \rho \frac{f_{d}}{8} U_{d}^{2}-\frac{1}{2} \rho\left(C_{d} \beta A_{v}\right) h_{c} P_{u}^{2} U_{d}^{2}=\delta \rho \frac{\partial\left(H \bar{K} U_{d}^{2}\right)}{\partial y} .
$$

Regions 1-4 are divided in Fig. 3 to illustrate the partition of the cross-section profile clearly. The interface between regions 1 and 2 is between vegetated and non-vegetated areas. The interface between regions 2 and 3 is located in the place where the depth-averaged streamwise velocity $U_{d}$ reaches $95 \%$ of the maximum $U_{d \max }$, which we think that the mixing layer is fully developed. Region 4 considers the effect of the shore wall and is set up with its boundary located in the place where $U_{d}$ reaches $95 \%$ of the maximum $U_{d \max }$. Two working conditions, namely, symmetrical and asymmetrical arrangements, are considered in this study. Only the diagram of the asymmetrical arrangement is selected for analysis because of the similarity of the region division in these two working conditions.

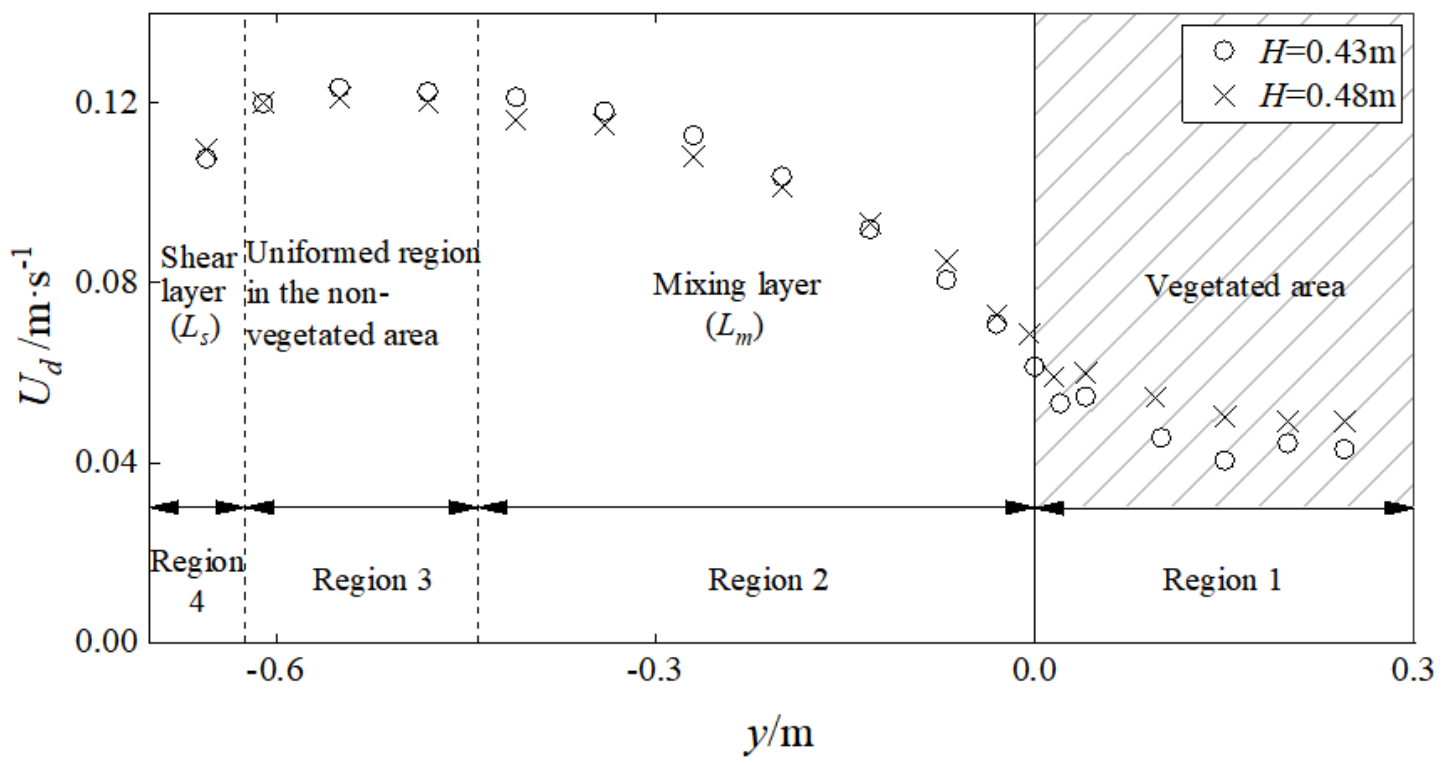


Fig. 3 Transverse distribution of depth-averaged streamwise velocity in the channel with the asymmetrical arrangement of FVIs

According to the division of the cross-section profile, the analytical solution to Eq.

209

(11) can be derived as follows:

210

211

(1) For the vegetated area, namely, region 1 in Fig. 3, $U_{d}$ is expressed as

$U_{d}^{(1)}=\left(A_{1} e^{\gamma_{1} y}+A_{2} e^{\gamma_{2} y}+\omega_{1}\right)^{1 / 2}$

212 where $\gamma_{1}=\frac{1}{H \lambda}\left(\frac{8}{f_{d}}\right)^{1 / 2}\left\{\overline{K_{1}}+\left[{\overline{K_{1}}}^{2}+\lambda\left(\frac{f_{d}}{8}\right)^{1 / 2}\left(\frac{m}{\delta} C_{d} \beta D h_{c} P_{u}^{2}+\frac{f_{d}}{4}\right)^{1 / 2}\right\}, \gamma_{2}=\frac{2}{H \lambda}\left(\frac{8}{f_{d}}\right)^{1 / 2} \overline{K_{4}}-\gamma_{1}\right.$, $\omega_{1}=\frac{g H S_{0}}{\frac{f_{d}}{8}+\frac{C_{d} \beta m D h_{c} P_{u}^{2}}{2 \delta}}$, and $A_{1}$ and $A_{2}$ are unknown constants.

214 (2) For the non-vegetated area, namely, region 2, region 3, and region 4 in Fig. 3, $U_{d}$ is 215 expressed as

$U_{d}^{(2)}=\left(A_{3} e^{\gamma_{3} y}+A_{4} e^{\gamma_{4} y}+\omega_{2}\right)^{1 / 2}$,

217 where $\gamma_{3}=\frac{1}{H \lambda}\left(\frac{8}{f_{d}}\right)^{1 / 2}\left\{\overline{K_{2}}+\left[{\overline{K_{2}}}^{2}+\lambda\left(\frac{f_{d}}{8}\right)^{1 / 2}\left(\frac{f_{d}}{4}\right)\right]^{1 / 2}\right\}, \gamma_{4}=\frac{2}{H \lambda}\left(\frac{8}{f_{d}}\right)^{1 / 2} \overline{K_{2}}-\gamma_{3}, \omega_{2}=\frac{8 g H S_{0}}{f_{d}}$, 218 and $A_{3}$ and $A_{4}$ are unknown constants.

$U_{d}^{(3)}=\left(A_{5} e^{\gamma_{5} y}+A_{6} e^{\gamma_{6} y}+\omega_{3}\right)^{1 / 2}$,

where $\quad \gamma_{5}=\frac{1}{H \lambda}\left(\frac{8}{f_{d}}\right)^{1 / 2}\left\{\overline{K_{3}}+\left[{\overline{K_{3}}}^{2}+\lambda\left(\frac{f_{d}}{8}\right)^{1 / 2}\left(\frac{f_{d}}{4}\right)\right]^{1 / 2}\right\}, \gamma_{6}=\frac{2}{H \lambda}\left(\frac{8}{f_{d}}\right)^{1 / 2} \overline{K_{3}}-\gamma_{5}, \omega_{3}=\frac{8 g H S_{0}}{f_{d}}$, and $A_{5}$ and $A_{6}$ are unknown constants.

$U_{d}^{(4)}=\left(A_{7} e^{\gamma_{7} y}+A_{8} e^{\gamma_{8} y}+\omega_{4}\right)^{1 / 2}$

where $\gamma_{7}=\frac{1}{H \lambda}\left(\frac{8}{f_{d}}\right)^{1 / 2}\left\{\overline{K_{4}}+\left[{\overline{K_{4}}}^{2}+\lambda\left(\frac{f_{d}}{8}\right)^{1 / 2}\left(\frac{f_{d}}{4}\right)\right]^{1 / 2}\right\}, \gamma_{8}=\frac{2}{H \lambda}\left(\frac{8}{f_{d}}\right)^{1 / 2} \overline{K_{4}}-\gamma_{7}, \omega_{4}=\frac{8 g H S_{0}}{f_{d}}$, and $A_{7}$ and $A_{8}$ are unknown constants.

Superscripts (1)-(4) of $U_{d}$ represent regions $1-4$ in Fig. 3, respectively. $\overline{K_{1}}-\overline{K_{4}}$ are the secondary flow coefficients in regions $1-4$, respectively. $f_{d}$ is the friction coefficient that will be specifically introduced in the later section. $A_{1}-A_{8}$ can be derived from the boundary conditions in the following section. 


\section{Boundary conditions for analytical solutions}

230

The flow structure under two experimental conditions of symmetrical and asymmetric arrangements of FVIs is explored in this study. Diagrams of the two experimental conditions are shown in Fig. 4, where $B$ is the width of the channel. Let $\alpha B$ and $(1-\alpha) B$ be the respective widths of vegetated and non-vegetated areas $(0 \leq \alpha \leq 1)$ to simplify the calculation.

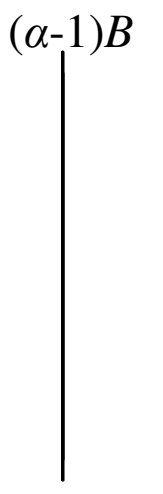

(a) Asymmetrical arrangement case

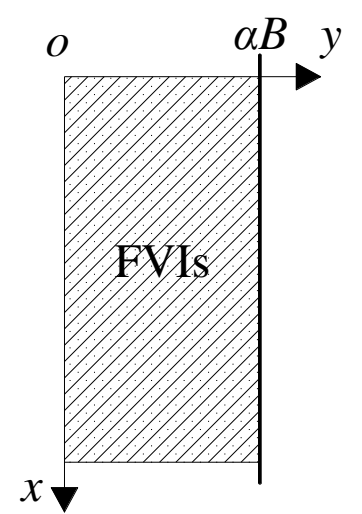

$x$

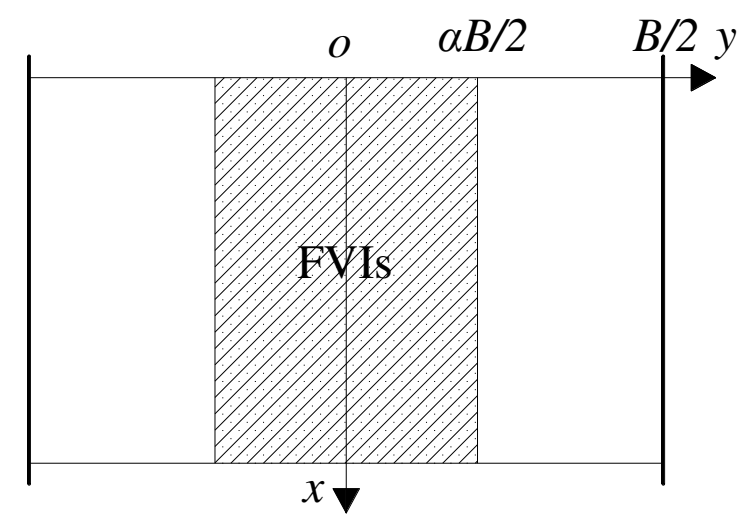

(b) Symmetrical arrangement case

Fig. 4 Diagrams of the two arrangement cases

Using suitable boundary conditions to obtain unknown coefficients $A_{1}-A_{8}$ is necessary to obtain solutions of $U_{d}$ for symmetric and asymmetric arrangements of FVIs.

(1) Boundary conditions for the asymmetrical arrangement of FVIs

a. $U_{d}^{(1)}=0$ for $y=\alpha B$ is obtained by utilizing the no-slip boundary condition in the vegetated side.

b. $U_{d}^{(4)}=0$ for $y=(\alpha-1) B$ is obtained by applying the no-slip boundary condition in the nonvegetated side.

c. $U_{d}^{(i)}=U_{d}^{(i+1)}$ according to the continuity of depth-averaged streamwise velocity at the interface between two adjacent regions.

d. $\partial U_{d}^{(i)} / \partial y=\partial U_{d}^{(i+1)} / \partial y$ due to the continuity of velocity gradient at the interface between two adjacent regions.

(2) Boundary conditions of the symmetrical arrangement of FVIs

a. The velocity distribution is symmetrical along the centerline of the channel, and thus the velocity gradient at the center is equal to zero, such that $\partial U_{d}^{(1)} / \partial y=0$ for $y=0$. 
b. $U_{d}^{(4)}=0$ for $y=B / 2$ is obtained by applying the no-slip boundary condition.

c. $U_{d}^{(i)}=U_{d}^{(i+1)}$ according to the continuity of depth-averaged streamwise velocity at the 253 interface between two adjacent regions.

d. $\partial U_{d}^{(i)} / \partial y=\partial U_{d}^{(i+1)} / \partial y$ because of the continuity of velocity gradient at the interface between two adjacent regions.

\section{Application principle and calibration coefficients}

The lateral eddy viscosity coefficient $\lambda$, friction coefficient $f_{d}$, porosity $\delta$, shape factor

$\beta$, depth-averaged drag coefficient $C_{d}$, and secondary flow coefficient $\bar{K}$ must be determined to calculate the lateral velocity distribution in the channel with FVIs. The channel cross section is subdivided into different subregions and suitable secondary flow coefficients are applied to each subregion using Eqs. (12)-(15) to establish the lateral distribution model of $U_{d}$. Considering the symmetrical arrangement of FVIs, only half of the cross section ought to be explored, which is then divided into four sub-regions as narrated above as well as the entire cross section in the asymmetrical arrangement of FVIs.

1. Transverse eddy viscosity coefficient $\lambda$

A constant "standard" value of $\lambda=0.067$ is introduced to the four subregions to simplify the calibration procedure and modeling process $(\lambda=\kappa / 6=0.4 / 6 \approx 0.067$, where $\kappa$ is the Karmen constant). Note that the change of $\lambda$ slightly affects the results of the SKM for the open-channel flow. Therefore, only the secondary flow coefficient $\bar{K}$ must be calibrated to simulate the transverse distribution of the streamwise velocity (Knight and Abril 1996; Abril 1997; Tang and Knight 2008).

2. Friction coefficient $f_{d}$

The derived calculation formula of the comprehensive friction coefficient $f_{d}$ mainly uses the relationship among the channel bed boundary shear stress $\tau_{g}$, floating island boundary shear stress $\tau_{c}$, and comprehensive boundary shear stress $\tau_{d}$, which is expressed as $\tau_{d}=\left(\chi_{g} \tau_{g}+\chi_{c} \tau_{c}\right) / \chi_{d}$.

Assuming that $\tau_{g}=\rho \frac{f_{g}}{8} U_{d_{g}}^{2}, \tau_{c}=\rho \frac{f_{c}}{8} U_{d_{c}}^{2}$, and $\tau_{d}=\rho \frac{f_{d}}{8} U_{d}^{2}$, the following equation is obtained: 
280

281

282

283

284

285

286

287

288

289

where $f_{g}$ and $f_{c}$ are the Darcy-Weisbach friction factors of the channel bed and floating island, respectively; $\chi_{g}$ and $\chi_{c}$ represent dimensionless wetted perimeters of the channel bed per unit width and floating island per unit width, respectively; and $\chi_{d}$ is the dimensionless comprehensive wetted perimeter per unit width, $\chi_{d}=\chi_{g}+\chi_{c}$.

According to the relationship between the depth-averaged streamwise velocity in the canopy region and the depth-averaged streamwise velocity of the total water depth $H$ in Eq. (5), $U_{d_{c}}=P_{u} U_{d}$. The depth-averaged streamwise velocity of the entire water depth $U_{d}=\frac{1}{H} \int_{0}^{H} U d z$ can be expressed using the depth-averaged streamwise velocity in the canopy region $U_{d_{c}}=\frac{1}{h_{c}} \int_{h_{g}}^{H} U d z$ and the depth-averaged streamwise velocity in the gap region $U_{d_{g}}=\frac{1}{h_{g}} \int_{0}^{h_{g}} U d z$, such that $H U_{d}=h_{c} U_{d_{c}}+h_{g} U_{d_{g}}$. Therefore, the relationship between $U_{d_{c}}$ and $U_{d_{g}}$ can be derived as follows

$$
U_{d_{c}} / U_{d_{g}}=\frac{P_{u}}{1+h_{c} / h_{g}} /\left(1-\frac{P_{u}}{1+h_{g} / h_{c}}\right)=P_{u}^{\prime} .
$$

$$
f_{d}=\frac{\chi_{g} f_{g}\left(P_{u} / P_{u}^{\prime}\right)^{2}+\chi_{c} f_{c} P_{u}^{2}}{\chi_{d}}=\frac{\chi_{g} f_{g}\left(P_{u} / P_{u}^{\prime}\right)^{2}+\chi_{c} f_{c} P_{u}^{2}}{\chi_{g}+\chi_{c}} .
$$

The expression of the friction coefficient is obtained by combining the commonly used Chezy formula with the Manning equation. Therefore, the friction coefficient of the channel bed and the floating island can be expressed as

$$
f_{g}=\frac{8 g n_{g}^{2}}{R_{g}^{1 / 3}}
$$

$$
f_{c}=\frac{8 g n_{c}^{2}}{R_{c}^{1 / 3}}
$$

where $n_{g}$ and $n_{c}$ represent Manning's roughness coefficients of the channel bed and the floating island, respectively, and $R_{g}$ and $R_{c}$ denote hydraulic radiuses of gap and canopy 
301

302

$303 \quad U_{d_{g}}=\frac{R_{g}^{2 / 3} J_{g}^{1 / 2}}{n_{g}}$,

$304 \quad U_{d_{c}}=\frac{R_{c}^{2 / 3} J_{c}^{1 / 2}}{n_{c}}$,

305

306

$$
R_{c}=\frac{1+\beta^{\prime}}{\frac{n_{g}^{3 / 2}}{n_{c}^{3 / 2} P_{u}^{\prime 3 / 2}}+\beta^{\prime}} R_{d} .
$$

where $J_{g}$ and $J_{c}$ are hydraulic slopes of gap and canopy regions, respectively. Considering that the flow condition in this research is steady and uniform, there is $J_{g}=J_{c}$. Accordingly, $U_{d_{c}}=P_{u}^{\prime} U_{d_{g}}$ is combined with Eqs. (21) and (22) to express the relationship between $R_{g}$ and $R_{c}$ as follows:

$$
\frac{R_{g}}{R_{c}}=\frac{n_{g}^{3 / 2}}{P_{u}^{3 / 2} n_{c}^{3 / 2}} \text {. }
$$

expressed as

$$
R_{d}=\frac{A_{d}}{\chi_{d}}=\frac{A_{g}+A_{c}}{\chi_{g}+\chi_{c}}=\frac{A_{g} / \chi_{g}+\left(A_{c} / \chi_{c}\right) \chi_{c} / \chi_{g}}{1+\chi_{c} / \chi_{g}}=\frac{n_{g}^{3 / 2} /\left(n_{c}^{3 / 2} P_{u}^{\prime 3 / 2}\right)+\beta^{\prime}}{1+\beta^{\prime}} R_{c},
$$

where $A_{g}$ and $A_{c}$ are areas of the gap and canopy regions, respectively; $A_{d}$ is the area of the entire cross section, $A_{d}=A_{g}+A_{c}$; and $\beta^{\prime}$ is the ratio of $\chi_{c}$ to $\chi_{g}, \beta^{\prime}=\chi_{c} / \chi_{g}$. We obtain the following equation on the basis of Eq. (24):

Thus, the comprehensive friction factor $f_{d}$ can be expressed by substituting Eqs. (19) and (20) and (23)-(25) into Eq. (18) as follows:

$$
f_{d}=\frac{8 g}{\chi_{g}+\chi_{c}}\left[\frac{n_{g}^{3 / 2} P_{u}^{\prime-3 / 2}+\beta^{\prime} n_{c}^{3 / 2}}{\left(1+\beta^{\prime}\right) R_{d}}\right]^{1 / 3}\left(\chi_{g} P_{u}^{2} P_{u}^{\prime-3 / 2} n_{g}^{3 / 2}+\chi_{c} P_{u}^{2} n_{c}^{3 / 2}\right) .
$$


$f_{d}=\frac{8 g}{\chi_{g}+\chi_{c}}\left[\frac{n_{g}^{3 / 2} P_{u}^{\prime-3 / 2}+\beta^{\prime} n_{c}^{3 / 2}}{\left(1+\beta^{\prime}\right) h_{g} / 2}\right]^{1 / 3}\left(\chi_{g} P_{u}^{2} P_{u}^{\prime-3 / 2} n_{g}^{3 / 2}+\chi_{c} P_{u}^{2} n_{c}^{3 / 2}\right)$.

The comprehensive hydraulic radius of the free water surface for free water surface areas is approximately equal to $h_{g}$. Thus, the comprehensive friction factor of the free water part can be expressed as

$f_{g}=\frac{8 g n_{g}^{2} P_{u}^{2} P_{u}^{\prime-2}}{h_{g}^{1 / 3}}$.

\section{Porosity $\delta$}

Porosity $\delta$ refers to the volume of pure water per unit water body in the case of vegetation and is expressed as

$\delta=1-V_{\text {vegetation }} / V_{\text {column }}$,

where $V_{\text {vegetation }}$ is the vegetation volume per unit vegetated area, $V_{\text {vegetation }}=\frac{1}{4} \pi m D^{2} h_{c}$, and $V_{\text {column }}$ is the volume of the water column for one water depth column per unit vegetated area, $V_{\text {volume }}=H$.

4. Shape factor $\beta$ and drag coefficient $C_{d}$

The results of earlier studies showed that both the drag coefficient $C_{d}$ and the shape factor $\beta$ may be considered equal to 1.0 (Schlichting 1960; Stone and Shen 2002; James 2004; Armanini et al. 2005; Rameshwaran and Shiono 2007; Tanino and Nepf 2008; Sun and Shiono 2009; Liu et al. 2013b).

\section{Secondary flow coefficient $\bar{K}$}

The secondary flow coefficient $\bar{K}$ is calibrated empirically in the current study to obtain the most consistent one with the lateral depth-averaged flow velocity distribution of the experiment and thus considered the optimal $\bar{K}$.

\section{Comparative analysis of results}

The reliability and validity of the analytical model is verified using the experimental results. Parameters used for modeling in both cases are listed in Table 2. Figs. 5-7 show the analytical results of $U_{d}$ for symmetrical and unsymmetrical cases with two different flow 
depths. Fig. 5 illustrates that the analytical results of the symmetrical case with large width ( $b$ $=0.6 \mathrm{~m})$ are consistent with the experimental results regardless of a high or low flow depth. The comparison of Figs. 5(a) and 5(b) shows that the velocity gradient $\partial U_{d} / \partial y$ at low water depth is larger than that at high water depth in the mixing layer. The rapid increase of $U_{d}$ with large water depth to the maximum from the vegetated area to the non-vegetated area is consistent with engineering practice. The velocity in the non-vegetated area at low water depth is slightly larger than that at high water depth. Moreover, values of the secondary flow coefficient $\bar{K}$ remain nearly unchanged in the vegetated area (region 1) with the increase of water depths but increase from $0.9 \%$ to $1.2 \%, 2.5 \%$ to $5.0 \%$, and $1.0 \%$ to $2.0 \%$ in regions 3,4 , and 5 of the non-vegetated area, respectively (Table 2).

Fig. 6 presents that the prediction of the model is also satisfactory in the symmetrical case with a small width $(b=0.3 \mathrm{~m})$. Similar to the aforementioned case, $U_{d}$ increases rapidly toward the maximum value at a low water depth and the maximum velocity value at low water depth slightly outweighs that at high water depth. However, some deviations exist between the symmetrical case with small width and that with large width. For example, values of the secondary flow coefficient $\bar{K}$ in region 1 in the small width case are one order of magnitude larger than those in the large width one and reach values at $0.5 \%$ and $-1.0 \%$ for low and high water depths, respectively. This phenomenon is likely due to the weakened resistance of vegetation to secondary flows along with the decrease of the width of the vegetated area (region 1) that enlarges the secondary flow coefficient in that area. Moreover, values of the secondary flow coefficient $\bar{K}$ change from $0.5 \%$ to $-1.0 \%$ as the water depth grows in the same region, thereby indicating the change in direction of the secondary flow's rotation, which is a different result from that of the large width case. Compared with the large width case, the velocity changes more gradually in the small width case due to the wider mixing layer.

The model can also successfully predict the lateral variation of depth-averaged streamwise velocity at low and high water depths for the asymmetrical case, as shown in Fig. 7. $U_{d}$ alters more sharply at low water depth and the maximum value it reaches is larger than that at high water depth in the mixing layer. Moreover, negative signs of the secondary flow coefficient $\bar{K}$ are contrary to the symmetrical cases, as presented in Table 2. The distinctive arrangement of FVIs may alter flow patterns in symmetrical and asymmetrical cases and 
cause this result. The modeled results are slightly smaller than the experimental data when $0.2 \mathrm{~m}<y<0.3 \mathrm{~m}$ likely because the shore wall friction is neglected.

\section{Table 2}

Parameters used in modeling the open-channel flow through FVIs

\begin{tabular}{ccccccccc}
\hline Cases & $\lambda_{1}$ & $\lambda_{2}$ & $\lambda_{3}$ & $\lambda_{4}$ & $\overline{K_{1}}(\%)$ & $\overline{K_{2}}(\%)$ & $\overline{K_{3}}(\%)$ & $\overline{K_{4}}(\%)$ \\
\hline Run 1 & 0.067 & 0.067 & 0.067 & 0.067 & 0.1 & 0.9 & 2.5 & 1.0 \\
Run 2 & 0.067 & 0.067 & 0.067 & 0.067 & 0.0 & 1.2 & 5.0 & 2.0 \\
Run 3 & 0.067 & 0.067 & 0.067 & 0.067 & 0.5 & 1.8 & 9.0 & 0.5 \\
Run 4 & 0.067 & 0.067 & 0.067 & 0.067 & -1.0 & 2.9 & 8.0 & 0.5 \\
Run 5 & 0.067 & 0.067 & 0.067 & 0.067 & -1.0 & -3.0 & -20.0 & 0.1 \\
Run 6 & 0.067 & 0.067 & 0.067 & 0.067 & -1.0 & -3.2 & -17.5 & -0.2 \\
\hline
\end{tabular}
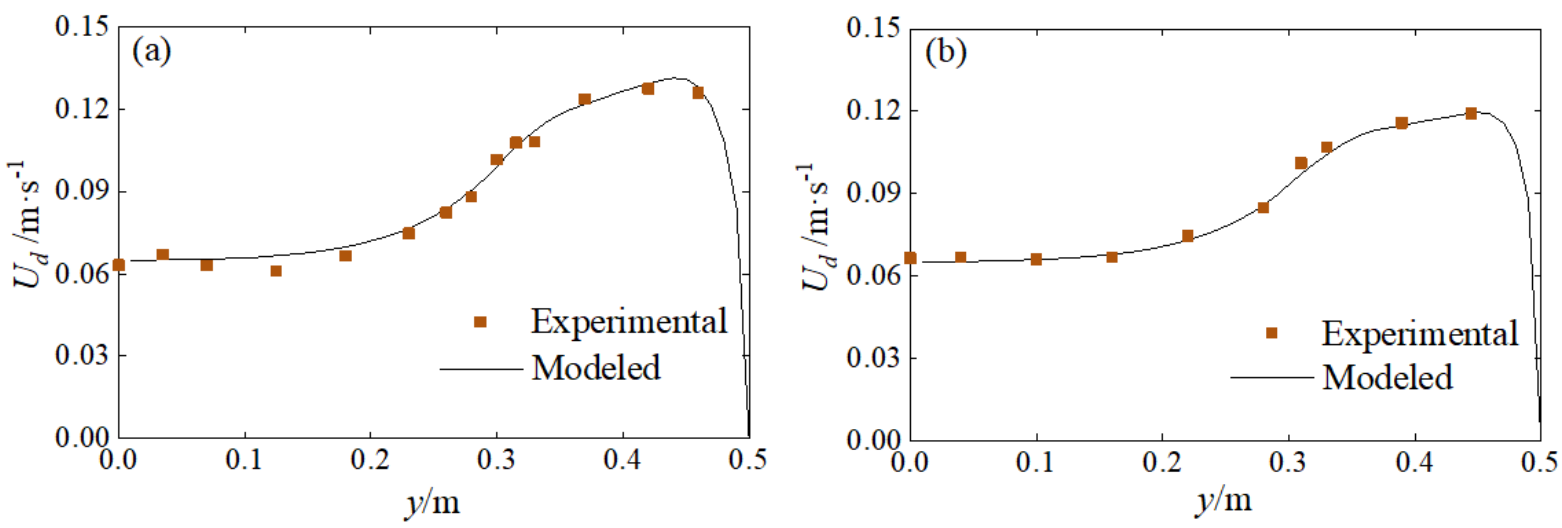

Fig. 5 Transverse variation of depth-averaged streamwise velocity $U_{d}$ for the symmetrical arrangement of FVIs with wide width $(b=0.6 \mathrm{~m})$ and two water depths of (a) $H$ $=0.43 \mathrm{~m}$, Run 1 and (b) $H=0.48 \mathrm{~m}$, Run 2
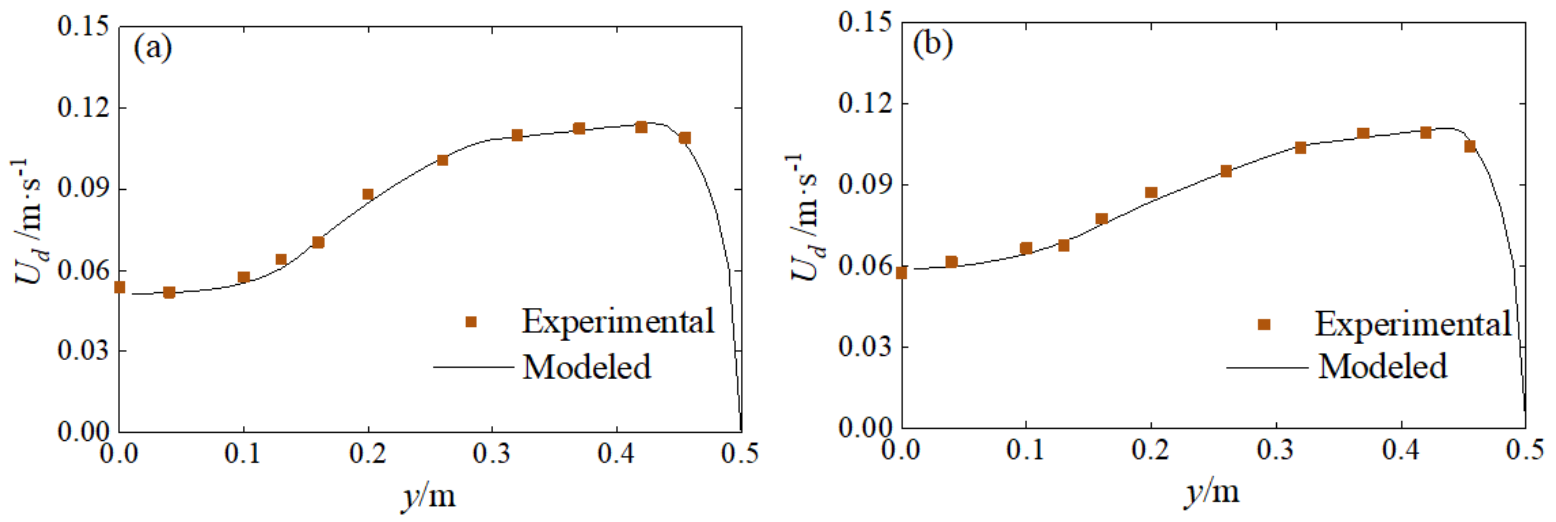
Fig. 6 Transverse variation of depth-averaged streamwise velocity $U_{d}$ for the symmetrical arrangement of FVIs with narrow width $(b=0.3 \mathrm{~m})$ and two water depths of (a) $H=0.43 \mathrm{~m}$, Run 3 and (b) $H=0.48 \mathrm{~m}$, Run 4
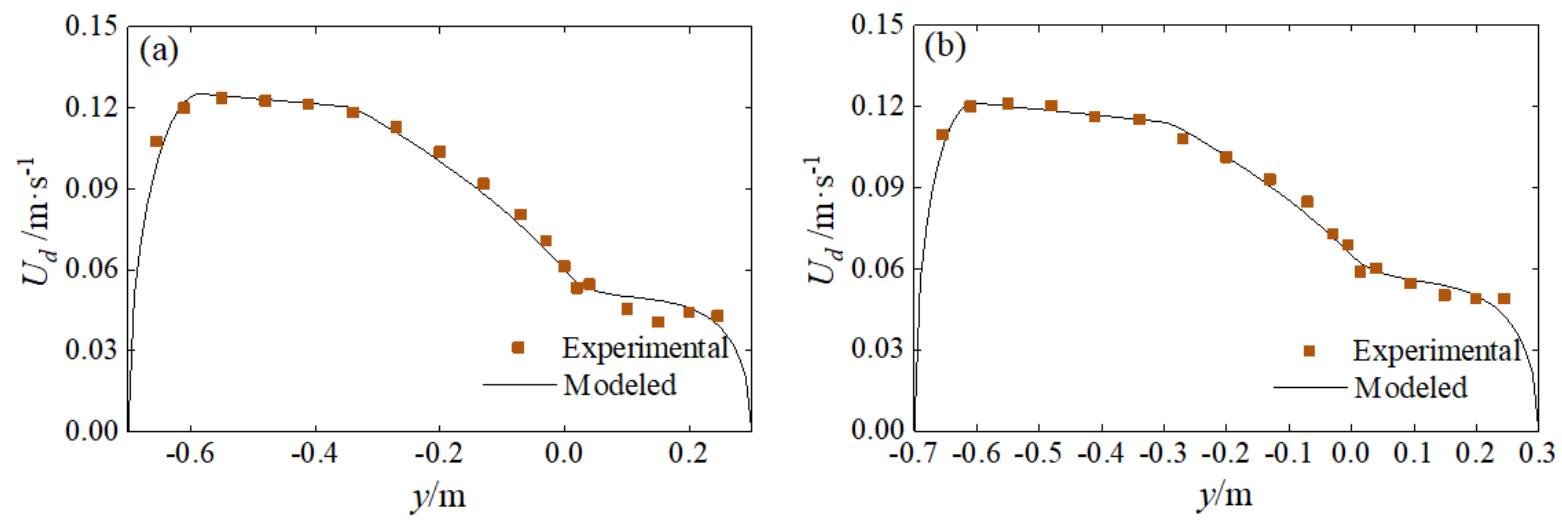

391

392

393

394

395

396

397

398

399

400

$401 \quad \overline{\varepsilon_{a}}=\frac{1}{N} \sum_{i=1}^{N} a b s\left(\varepsilon_{a i}\right)$, $=0.48 \mathrm{~m}$, Run 6

Fig. 7 Transverse variation of depth-averaged streamwise velocity $U_{d}$ for the asymmetrical arrangement of FVIs with two water depths of (a) $H=0.43 \mathrm{~m}$, Run 5 and (b) $H$

Error statistics, including the calculation of average absolute error $\overline{\varepsilon_{a}}$ and average relative error $\overline{\varepsilon_{r}}$ are carried out to compare the model results with the measured data, as shown in Table 3. The absolute error is expressed as

$\varepsilon_{a}=\left(U_{d}\right)_{\text {computed }}-\left(U_{d}\right)_{\text {measured }}$,

where subscripts "computed" and "measured" represent computed and measured values of $U_{d}$, respectively. The average absolute error based on Eq. (30) is calculated as

where $N$ represents the number of measuring perpendiculars in the cross section for each case. The relative error $\varepsilon_{r}$ based on Eq. (30) is expressed as

404

$\varepsilon_{r}=\frac{\varepsilon_{a}}{\left(U_{d}\right)_{\text {measured }}}$,

405 and the average relative error $\overline{\varepsilon_{r}}$ is expressed as

$406 \quad \overline{\varepsilon_{r}}=\left[\frac{1}{N} \sum_{i=1}^{N} a b s\left(\varepsilon_{r i}\right)\right] \times 100 \%$. 

errors are within $0.004 \mathrm{~m} / \mathrm{s}$, and the peak of the maximum average absolute error $\overline{\varepsilon_{a}}$ of Run 5 case is at $0.0031 \mathrm{~m} / \mathrm{s}$. Average relative errors vary from $1.99 \%$ to $4.74 \%$. The prediction result of the Run 2 case is the most accurate among all the cases, with minimum values of $\overline{\varepsilon_{a}}$ and $\overline{\varepsilon_{r}}$ equal to $0.0022 \mathrm{~m} / \mathrm{s}$ and $2.30 \%$, respectively. The model can appropriately predict the depth-averaged streamwise velocity according to error statistics.

Table 3

Error statistics of depth-averaged streamwise velocities for all cases

\begin{tabular}{ccccccc}
\hline Cases & Run 1 & Run 2 & Run 3 & Run 4 & Run 5 & Run 6 \\
\hline Average absolute error (m/s) $\overline{\varepsilon_{a}}$ & 0.0025 & 0.0022 & 0.0016 & 0.0016 & 0.0031 & 0.0022 \\
Average relative error $(\%) \overline{\varepsilon_{r}}$ & 3.10 & 2.30 & 2.12 & 1.99 & 4.74 & 3.14 \\
\hline
\end{tabular}
cases at a water depth of $H=0.43 \mathrm{~m}$ are performed to determine their influence on the transverse variation of $U_{d}$ and signs of $\bar{K}$, as shown in Fig. 8. Three conditions are considered for each case in this study. $\overline{K_{1}}=\overline{K_{2}}=\overline{K_{3}}=\overline{K_{4}}=0$, $\overline{K_{1}}=1 \%, \overline{K_{2}}=1 \%, \overline{K_{3}}=1 \%, \overline{K_{4}}=1 \%$, adopted for the symmetrical case. $\quad \overline{K_{1}}=\overline{K_{2}}=\overline{K_{3}}=\overline{K_{4}}=0$, $\overline{K_{1}}=-2 \%, \overline{K_{2}}=-2 \%, \overline{K_{3}}=-20 \%, \overline{K_{4}}=-0.2 \%$, and $\overline{K_{1}}=-2 \%, \overline{K_{2}}=-2 \%, \overline{K_{3}}=20 \%, \overline{K_{4}}=-0.2 \%$ are applied for the asymmetrical case. Other coefficients not mentioned in this section remain stable, as shown in the aforementioned sections. Fig. 8 shows that errors of both cases between the analysis and experimental results are large when the secondary flow is ignored. Hence, the secondary flow must be considered. The results obtained are inaccurate compared with the analysis results, which are relatively close to numerical values adopted in this study, when the sign of only one coefficient is changed and the sign and size of the three other coefficients remain unchanged (signs of $\overline{K_{1}}$ and $\overline{K_{3}}$ are changed in this study for symmetrical and asymmetrical cases, respectively). The results obtained are satisfactory only when signs of second flow coefficients $\bar{K}$ remain stable with those presented in Table 2. Hence, secondary flow coefficient symbols used in this study are appropriate. 

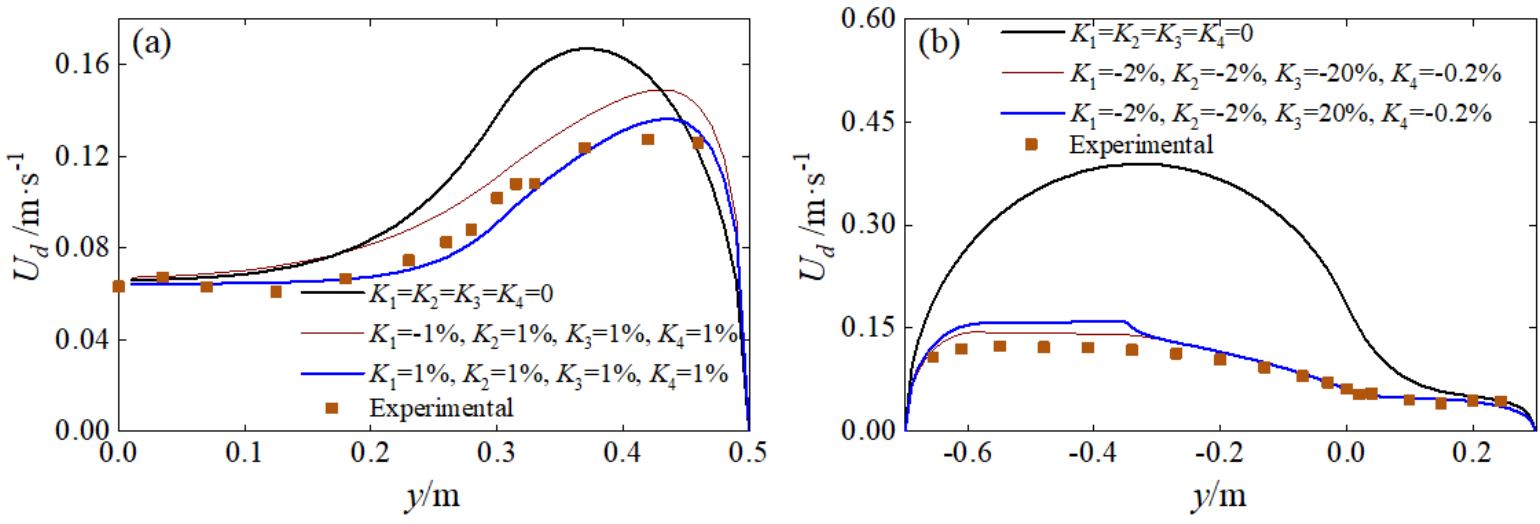

432

Fig. 8 Influence of the secondary flow on the transverse variation of $U_{d}$ for symmetrical and asymmetrical cases at a water depth of $H=0.43 \mathrm{~m}$ : (a) Run 1 (b) Run 5

\section{Conclusions}

The lateral distribution of depth-averaged streamwise velocity for the steady uniform flow in the open channel with symmetrical and asymmetrical arrangements of FVIs based on the $\mathrm{N}-\mathrm{S}$ equation is explored in this study. The canopy drag force is added to the $\mathrm{N}-\mathrm{S}$ equation as the additional resistance term, and the governing equation is solved with suitable boundary conditions. The cross section is divided into four calculation regions according to flow characteristics and the model layout. Calculation methods of six necessary parameters utilized in each region, namely, lateral eddy viscosity coefficient $\lambda$, friction coefficient $f_{d}$, porosity $\delta$, shape factor $\beta$, drag coefficient $C_{d}$, and secondary flow coefficient $\bar{K}$, are discussed in detail. The secondary flow coefficient $\bar{K}$ plays an important role in the prediction of the lateral distribution of depth-averaged streamwise velocity. If the effect of the secondary flow is neglected, then predicting depth-averaged velocities of the openchannel flow with FVIs is difficult. Analytical solutions of the lateral distribution of depthaveraged velocities are presented for symmetrical and asymmetrical cases. The consistency between the calculated results of the theoretical solution and experimental data indicated that the model can effectively predict the lateral distribution of the depth-averaged streamwise velocity in the open-channel flow with FVIs.

Although some theoretical results have been obtained using the proposed analytical model, the universality of these theoretical results requires further investigations. Meanwhile, limitations exist in the proposed analytical model (i.e., Eqs. (12)-(15)). The analytical model is unsuitable and infeasible when the flow state fails to satisfy the steady uniform flow 
456 condition. Moreover, model parameters need to be modified under different experimental conditions and additional work is needed to provide detailed references.

\section{$458 \quad$ Nomenclature}

459 The following symbols are used in this study:

$$
\begin{aligned}
& A_{1}-A_{8}=\text { Integration constants in Eqs. (12)-(15) } \\
& A_{v}=\text { Projected area of canopy per unit volume in the longitudinal direction } \\
& \left(\mathrm{m}^{-1}\right) \\
& A_{d}=\text { Area of the entire cross section }\left(\mathrm{m}^{2}\right) \\
& b=\text { Width of floating vegetated islands }(\mathrm{m}) \\
& B=\text { Flume width (m) } \\
& C_{b}=\text { Bed friction coefficient (-) } \\
& C_{d}=\text { Drag force coefficient (-) } \\
& D=\text { Canopy diameter }(\mathrm{m}) \\
& f_{d}=\text { Darcy-Weisbach comprehensive friction factor (-) } \\
& F_{v}=\text { Drag force, as defined by Eq. (2) }\left(\mathrm{N} / \mathrm{m}^{3}\right) \\
& g=\text { Gravitational acceleration }\left(\mathrm{m} / \mathrm{s}^{2}\right) \\
& h_{c}=\text { Height of the root canopy }(\mathrm{m}) \\
& h_{g}=\text { Height of the gap region (m) } \\
& H=\text { Flow depth }(\mathrm{m}) \\
& \bar{K}=\text { Secondary flow coefficient }(-) \\
& m=\text { Number of columns per bed area }\left(\mathrm{m}^{-2}\right) \\
& n=\text { Manning's roughness coefficient (-) } \\
& P_{u}=\text { Scale parameter between } U_{d_{c}} \text { and } U_{d}(-) \\
& P_{u}^{\prime}=\text { Scale parameter between } U_{d_{c}} \text { and } U_{d_{g}}(-) \\
& Q=\text { Flow rate }\left(\mathrm{m}^{3} / \mathrm{s}\right) \\
& R=\text { Hydraulic radius }(\mathrm{m}) \\
& S_{0}=\text { Channel bed slope (-) } \\
& u^{\prime}, v^{\prime}, w^{\prime}=\text { Fluctuating velocities in } x, y \text {, and } z \text { directions }(\mathrm{m} / \mathrm{s}) \\
& U_{d}=\text { Depth-averaged streamwise velocity }(\mathrm{m} / \mathrm{s}) \\
& U_{d_{c}}=\text { Depth-averaged streamwise velocity in the canopy region }(\mathrm{m} / \mathrm{s}) \\
& U_{d_{g}}=\text { Depth-averaged streamwise velocity in the gap region }(\mathrm{m} / \mathrm{s})
\end{aligned}
$$




$$
\begin{aligned}
U_{*}= & \text { Local shear velocity }(\mathrm{m} / \mathrm{s}) \\
V_{\text {column }}= & \text { Volume of the water depth column per unit vegetated bottom area }(\mathrm{m}) \\
V_{\text {vegetation }}= & \text { Volume occupied by the vegetation per unit vegetated bottom area } \\
& (\mathrm{m}) \\
x, y, z= & \text { Streamwise, lateral, and vertical directions }(-) \\
\alpha= & \text { Coefficients in Eq. }(5)(-) \\
\beta= & \text { Shape factor }(-) \\
\delta= & \text { Porosity }(-) \\
\lambda= & \text { Lateral dimensionless eddy viscosity }(-) \\
\kappa= & \text { Karman constant }(-) \\
\gamma_{1-8}, w_{1-4}= & \text { Coefficients in Eqs. }(12)-(15) \\
\tau_{y x}, \tau_{z x}= & \text { Reynolds shear stresses on planes perpendicular to } y \text { - and } z \text {-directions, } \\
\frac{\tau_{y x}=}{2} & \text { Despectively }\left(\mathrm{N} / \mathrm{m}^{2}\right) \\
\tau_{d}= & \text { Dopth-averaged Reynolds shear stresses on planes perpendicular to } \\
\varepsilon_{y x}= & \text { Dimensionless wetted perimeter per unit width }(-) \\
g, c= & \text { Abbreviations of lower gap and upper canopy regions }
\end{aligned}
$$

\section{Declarations}

461 Acknowledgements The authors gratefully acknowledge their family, teachers, and classmates for their help in making this study more meaningful.

Data availability The datasets used or analyzed during the current study are available from

464 the corresponding author on reasonable request.

Author contribution Wenxin Huai proposed the idea of this study. Xuecheng Fu did the majority of calculations, writing and editing. Feifei Wang revised the manuscript. The experiment was designed by Wenxin Huai and Mengyang Liu, and performed by Xuecheng Fu and Feifei Wang. All authors read and approved the final manuscript.

469 Funding This work was financially supported by the National Natural Science Foundation of

470 China [grant numbers 52020105006 and 11872285].

Ethics approval and consent to participate Not applicable. 
Consent for publication Not applicable.

473 Competing interests The authors declare that they have no competing interests.

\section{$474 \quad$ References}

475 Abril JB (1997) Numerical modelling of turbulent flow, sediment transport and flood routing 476 using the finite element method. Dissertation, University of Birmingham

477 Armanini A, Righetti M, Grisenti P (2005) Direct measurement of vegetation resistance in 478 prototype scale. J Hydraul Res 43(5):481-487. https://doi.org/10.1080/00221680509500146

479 Billore SK, Sharma JK (2009) Treatment performance of artificial floating reed beds in an 480 experimental mesocosm to improve the water quality of river Kshipra. Water Sci Technol 481 60(11):2851-2859. https://doi.org/10.2166/wst.2009.731

482 Bonakdari H (2012) Establishment of relationship between mean and maximum velocities in 483 narrow sewers. J Environ 113:474-480. 484 https://doi.org/10.1016/j.jenvman.2012.10.016

485 Chen G, Huai WX, Han J, Zhao MD (2010) Flow structure in partially vegetated rectangular 486 channels. J Hydrodyn 22(4):590-597. https://doi.org/10.1016/S1001-6058(09)60092-5

487 Chua LH, Tan SB, Sim CH, Goyal MK (2012) Treatment of baseflow from an urban 488 catchment by a floating wetland system. Ecol Eng 49:170-180. 489 https://doi.org/10.1016/j.ecoleng.2012.08.031

490 Devi K, Khatua KK (2016) Prediction of depth averaged velocity and boundary shear 491 distribution of a compound channel based on the mixing layer theory. Flow Meas Instrum 492 50:147-157. https://doi.org/10.1016/j.flowmeasinst.2016.06.020

493 Downing-Kunz M, Stacey M (2011) Flow-induced forces on free-floating macrophytes. 494 Hydrobiologia 671(1):121-135. https://doi.org/10.1007/s10750-011-0709-1

495 Ervine DA, Babaeyan-Koopaei K, Sellin RHJ (2000) Two-dimensional solution for straight 496 and meandering overbank flows. J Hydraul Eng 126(9):653-669. 497 https://doi.org/10.1061/(ASCE)0733-9429(2000)126:9(653)

498 Fernandes JN, Leal JB, Cardoso AH (2014) Improvement of the lateral distribution method 499 based on the mixing layer theory. Adv Water Resour 69(4):159-167. 500 https://doi.org/10.1016/j.advwatres.2014.04.003 
501 Huai WX, Xu ZG, Yang ZH, Zeng YH (2008) Two dimensional analytical solution for a partially vegetated compound channel flow. Appl Math Mech 29(8):1077-1084. https://doi.org/10.1007/s10483-008-0811-y

Huai WX, Gao M, Zeng YH, Li D (2009) Two-dimensional analytical solution for compound channel flows with vegetated floodplains. Appl Math Mech 30(9):1121-1130. https://doi.org/10.1007/s10483-009-0906-Z

Huai WX, Geng C, Zeng YH, Yang ZH (2011) Analytical solutions for transverse distributions of stream-wise velocity in turbulent flow in rectangular channel with partial vegetation. Appl Math Mech (Engl Ed) 32(4):459-468. https://doi.org/10.1007/s10483-011$\underline{1430-6}$

Hwang L, LePage BA (2011) Floating islands-An alternative to urban wetlands. In: Wetlands. Springer, Dordrecht, pp 237-250

Huai WX, Wang W, Zeng YH (2013) Two-layer model for open channel flow with submerge flexible vegetation. Hydraul

Res 51(6):708-718. https://doi.org/10.1080/00221686.2013.818585

Huai W, Li C (2016) Longitudinal dispersion in open channel flow with suspended canopies. Water Sci Technol 74(3):722-728. https://doi.org/10.2166/wst.2016.236 James CS, Birkhead AL, Jordanova AA, O’Sullivan JJ (2004) Flow resistance of emergent vegetation. J Hydraul Res 42(4):390-8. https://doi.org/10.1080/00221686.2004.9728404

Knight DW, Abril JB (1996) Refined calibration of a depth-averaged model for turbulent flow in a compound channel. Proceedings of the Institution of Civil Engineers-Water Maritime and Energy 118(3):151-159. https://doi.org/10.1680/iwtme.1996.28682

Liu C, Luo X, Liu X, Yang K (2013b) Modeling depth-averaged velocity and bed shear stress in compound channels with emergent and submerged vegetation. Adv Water Resour 60:148159. https://doi.org/10.1016/j.advwatres.2013.08.002

Liu C, Shan YQ, Yang KJ, Liu XN (2013a) The characteristics of secondary flows in compound channels with vegetated floodplains. J Hydrodyn 25:422-429. https://doi.org/10.1016/S1001-6058(11)60381-9

Liu C, Shan YQ, Lei JR, Nepf HM (2019) Floating treatment islands in series along a channel: Resour 129:222-231. https://doi.org/10.1016/j.advwatres.2019.05.011 
532 Nahlik AM, Mitsch WJ (2006) Tropical treatment wetlands dominated by free-floating macrophytes for water quality improvement in Costa Rica. Ecol Eng 28(3):246-257. https://doi.org/10.1016/j.ecoleng.2006.07.006 Plew DR (2011) Depth-averaged drag coefficient for modeling flow through suspended canopies. J Hydraul Eng 137(2):234-247. https://doi.org/10.1061/(ASCE)HY.1943$\underline{7900.0000300}$

Rameshwaran P, Shiono K (2007) Quasi two-dimensional model for straight overbank flows through emergent vegetation on floodplains. J Hydraul Res 45(3):302-315. https://doi.org/10.1080/00221686.2007.9521765

Schlichting H (1960) Boundary layer theory. McGraw-Hill, New York

Shiono K, Knight DW (1991) Turbulent open-channel flows with variable depth across the channel. J Fluid Mech 222(1):617-646. https://doi.org/10.1017/S0022112091001246 Stone BM, Shen HT (2002) Hydraulic resistance of flow in channels with cylindrical roughness. J Hydraul Eng 128(5):500-6. https://doi.org/10.1061/(ASCE)07339429(2002)128:5(500)

Sun X, Shiono K (2009) Flow resistance of one-line emergent vegetation along the floodplain edge of a compound open channel. Adv Water Resour 32(3):430-438. https://doi.org/10.1016/j.advwatres.2008.12.004

Tanner CC, Headley TR (2011) Components of floating emergent macrophyte treatment wetlands influencing removal of stormwater pollutants. Ecol Eng 37(3):474-486. https://doi.org/10.1016/j.ecoleng.2010.12.012 Tang X; Knight DW (2008) Lateral depth-averaged velocity distributions and bed shear in rectangular compound channels. J Hydraul Eng 134(3):1337-1342. https://doi.org/10.1061/(ASCE)0733-9429(2008)134:9(1337) Tanino Y, Nepf HM (2008) Laboratory investigation of mean drag in a random array of rigid, emergent cylinders. J Hydraul Eng 134(1):34-41. https://doi.org/10.1061/(ASCE)07339429(2008)134:1(34)

White BL, Nepf HM (2008) A vortex-based model of velocity and shear stress in a partially channel. Water

Resour

Res 44(1):1-15.

561 https://doi.org/10.1029/2006WR005651 
562 Wang FF, Huai WX, Liu MY, Fu XC (2020) Modeling depth-averaged streamwise velocity in 563 straight trapezoidal compound channels with ice cover. J Hydrodyn 585:123446. 564 https://doi.org/10.1016/j.jhydrol.2019.124336

565 Yang KJ, Cao SY, Knight DW (2007) Flow patterns in compound channels with vegetated 566 floodplains. J Hydraul Eng 133(2):148-159. https://doi.org/10.1061/(ASCE)0733$567 \quad \underline{9429(2007) 133: 2(148)}$

568 Zhong Y, Huai WX, Chen G (2019) Analytical model for lateral depth-averaged velocity 569 distributions in rectangular Ice-Covered channels. J Hydraul Eng 145(1):04018080. 570 https://doi.org/10.1061/(ASCE)HY.1943-7900.0001557 


\section{Figures}

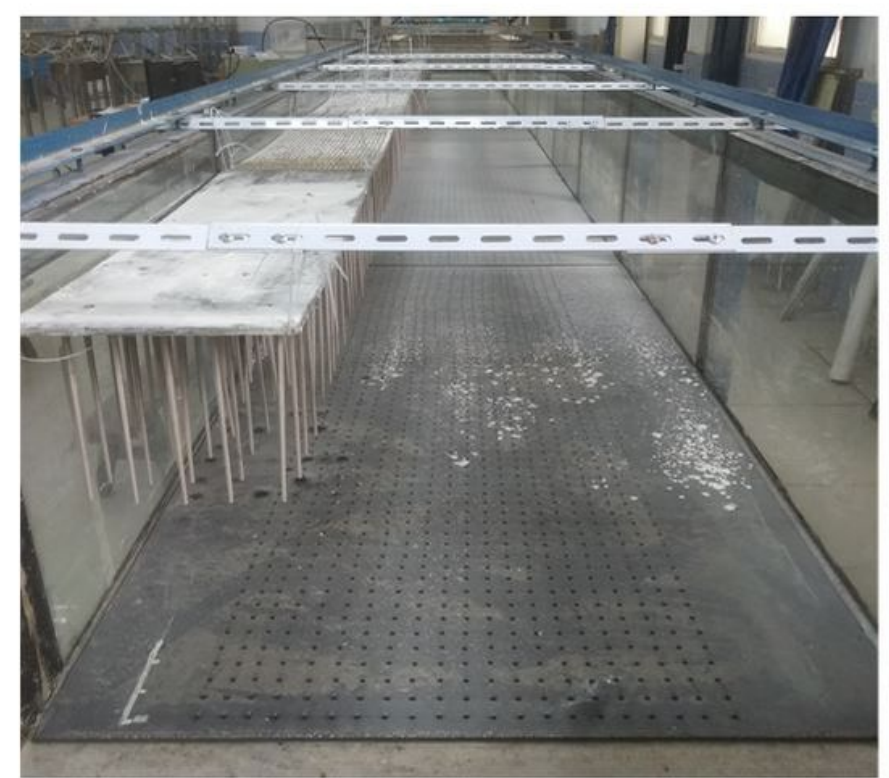

(a) Asymmetrical arrangement case

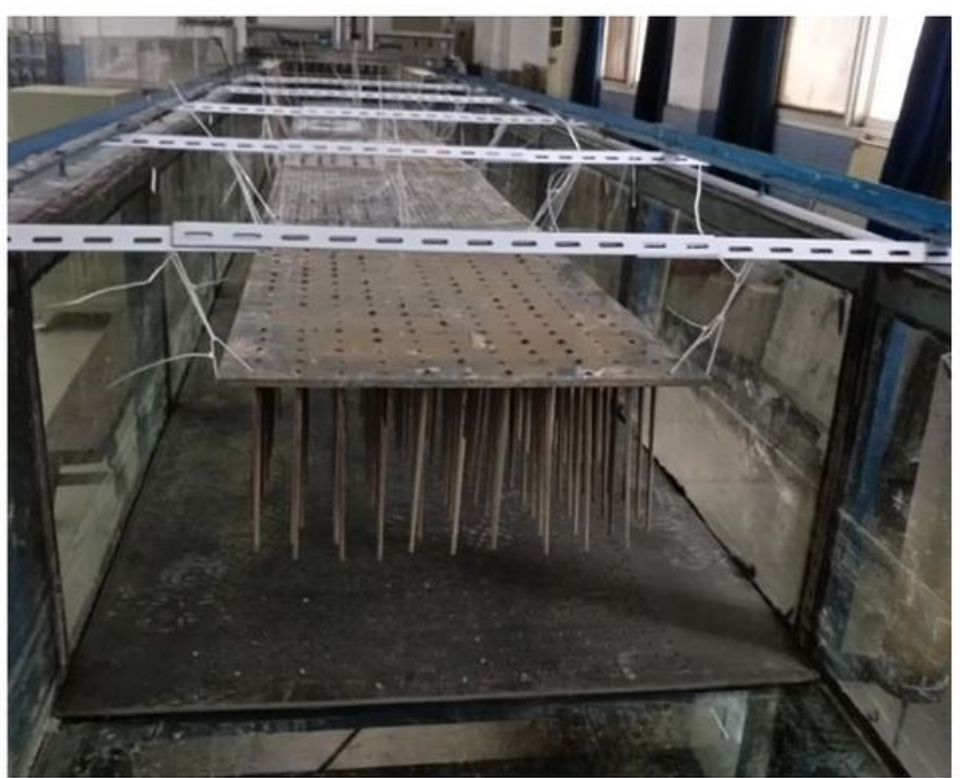

(b) Symmetrical arrangement case

Figure 1

Global view of the channel with different FVI arrangements 
(a)

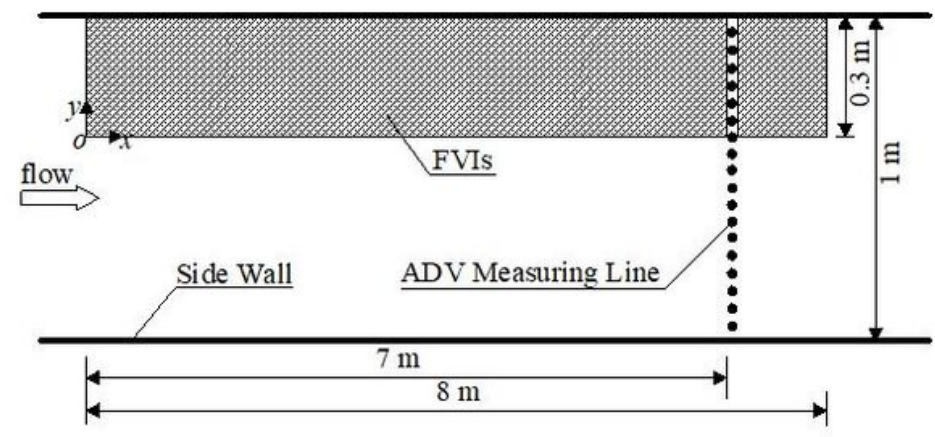

(c)

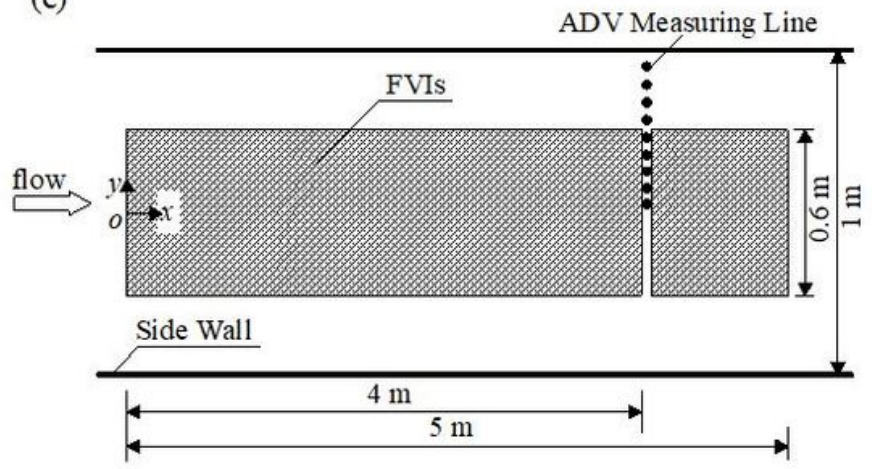

(b)

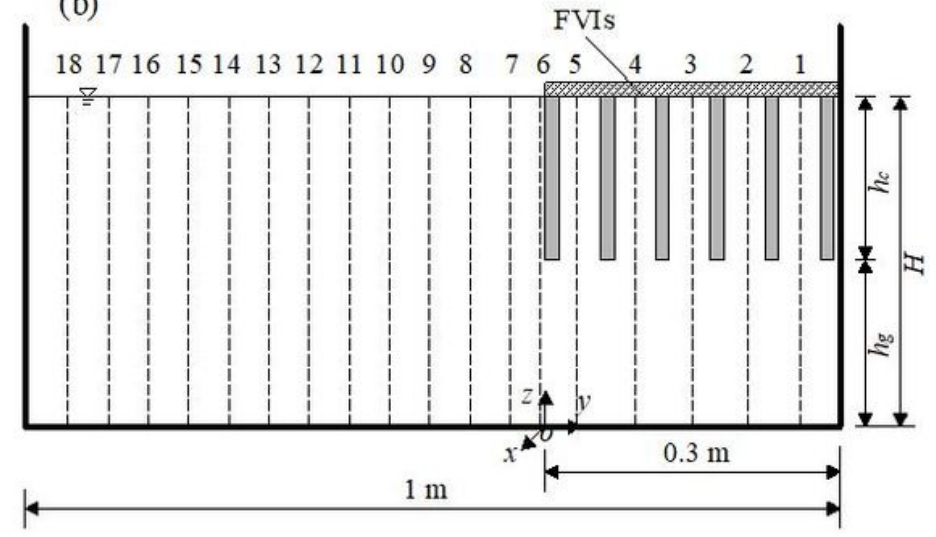

(d)

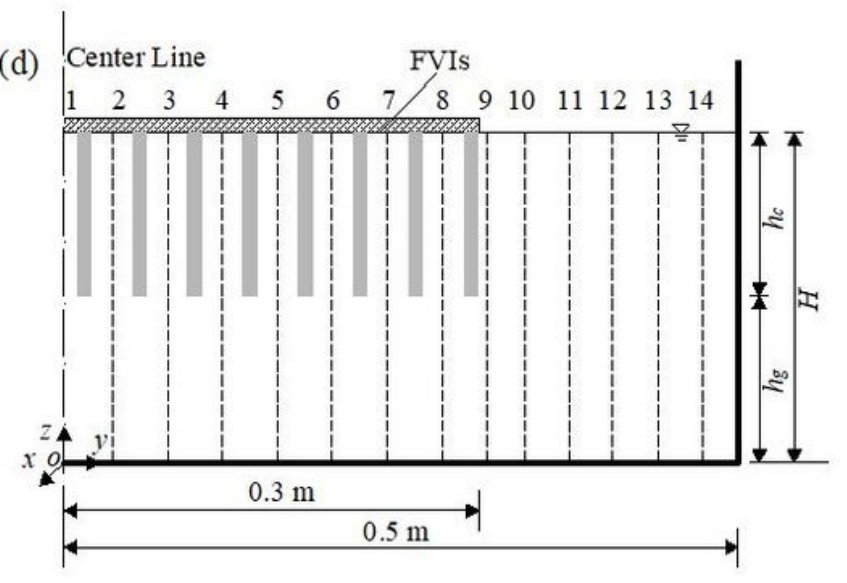

Figure 2

Diagrams of the FVI layout in the laboratory flume: (a) Top view of the asymmetrical arrangement case; (b) Cross-section profile of the asymmetrical arrangement case; (c) Top view of the symmetrical arrangement case; (d) Cross-section profile of the symmetrical arrangement case with the canopy height hc, gap height hg, and water depth $\mathrm{H}$ 


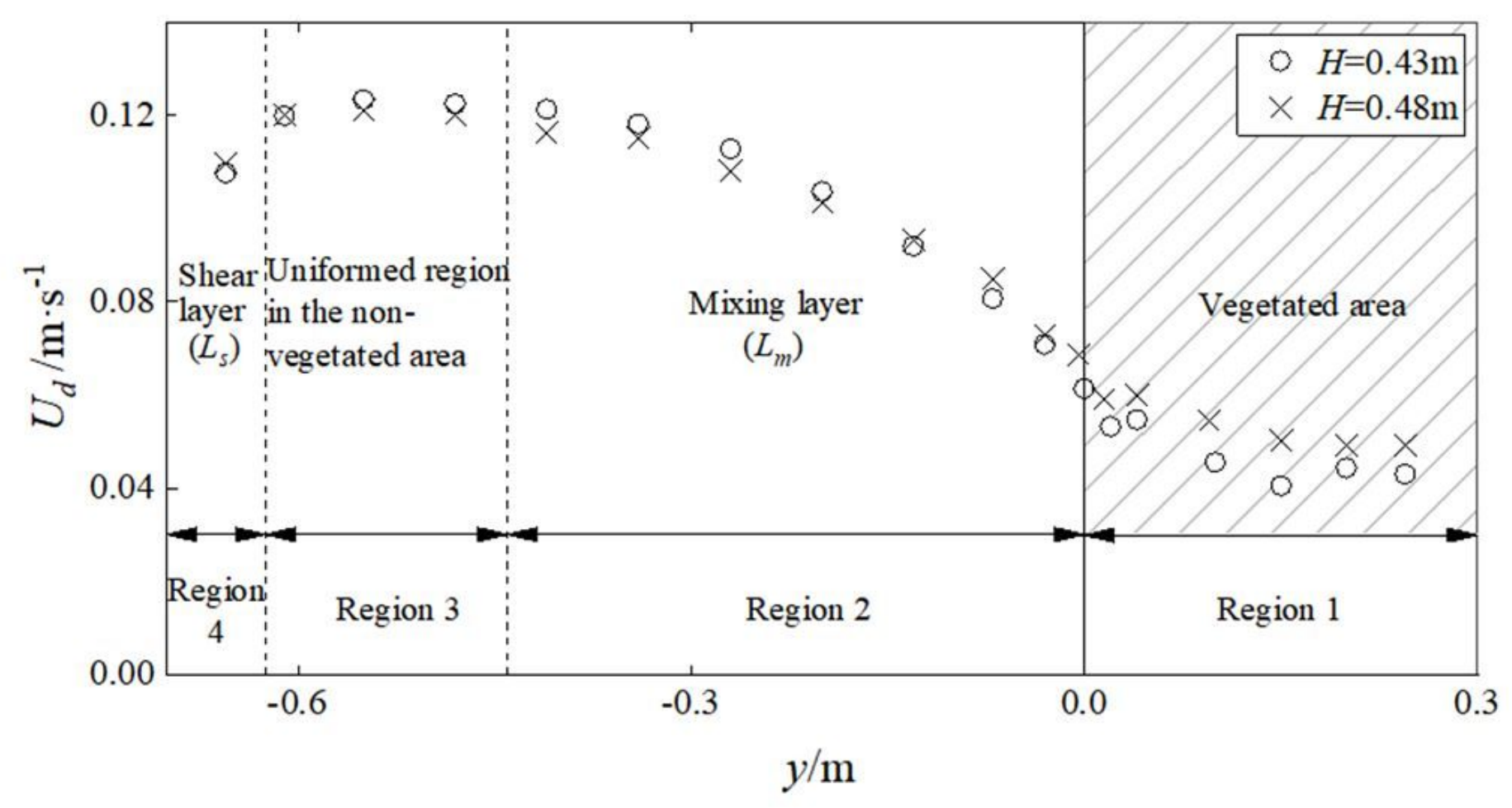

Figure 3

Transverse distribution of depth-averaged streamwise velocity in the channel with the asymmetrical arrangement of FVls
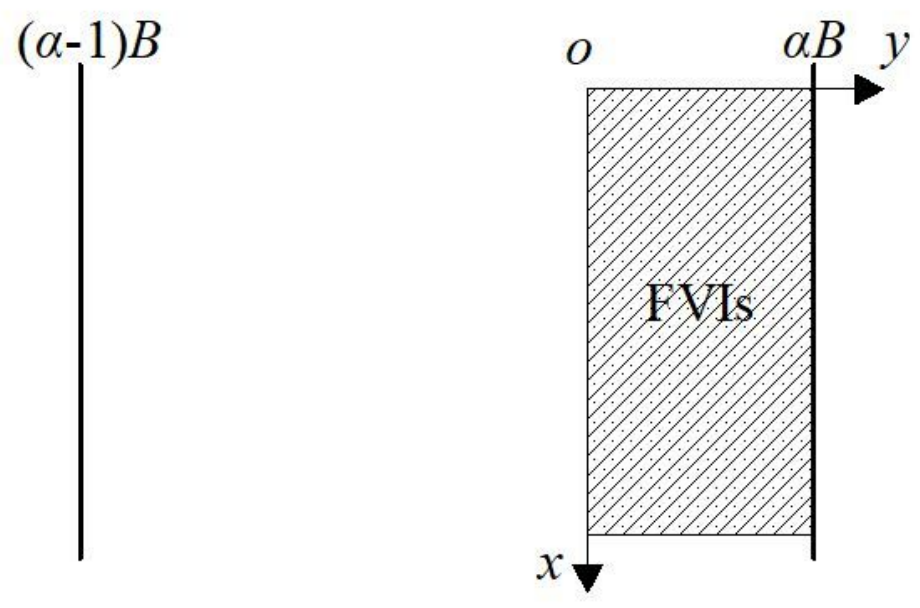

(a) Asymmetrical arrangement case

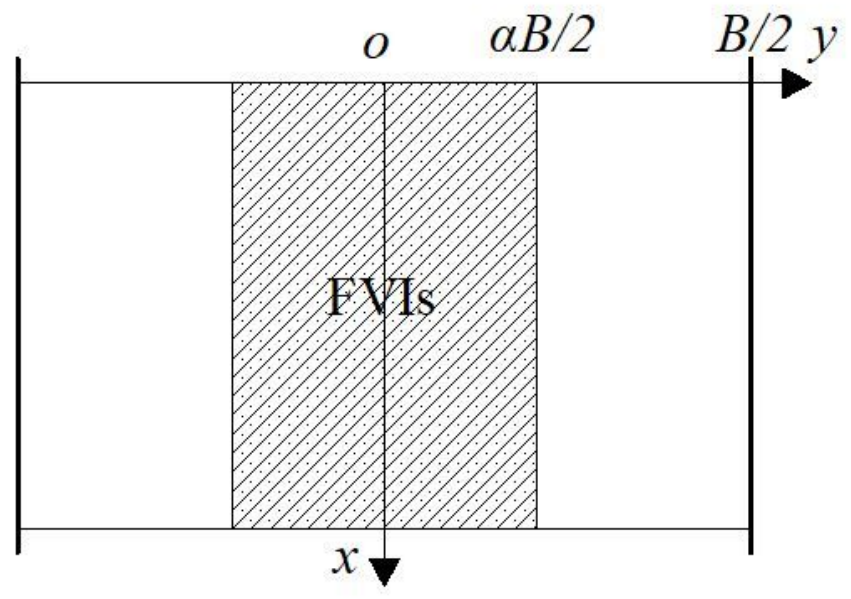

(b) Symmetrical arrangement case

Figure 4

Diagrams of the two arrangement cases 

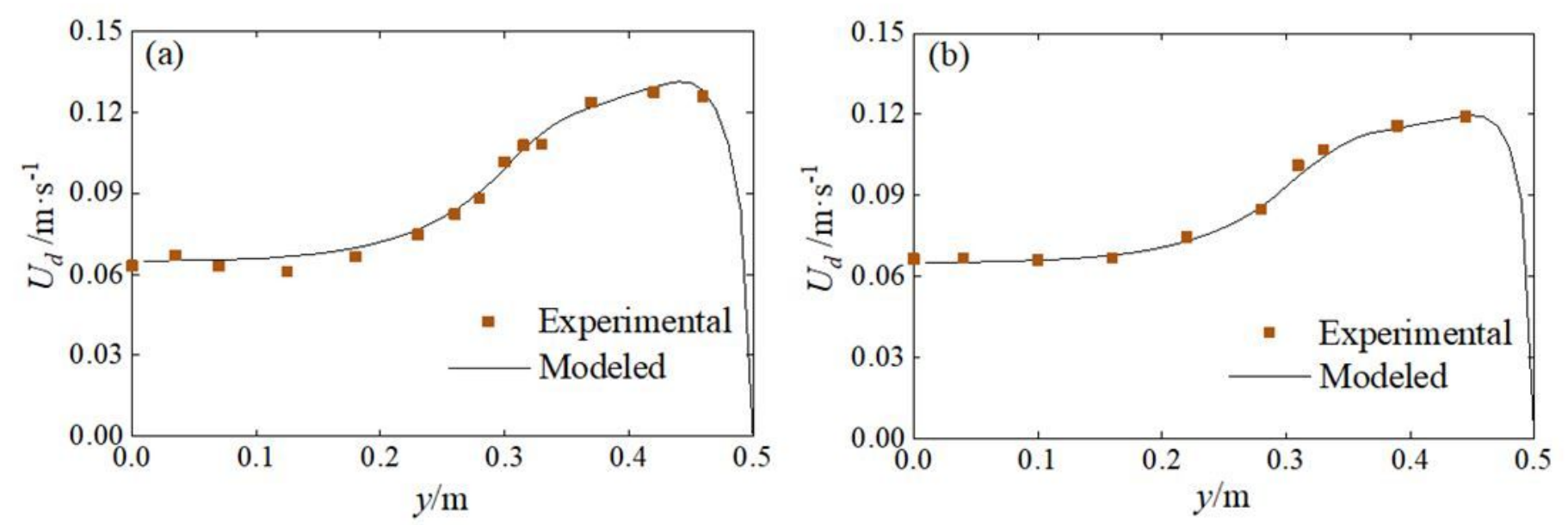

\section{Figure 5}

Transverse variation of depth-averaged streamwise velocity Ud for the symmetrical arrangement of FVls with wide width $(b=0.6 \mathrm{~m}$ ) and two water depths of $(\mathrm{a}) \mathrm{H}=0.43 \mathrm{~m}$, Run 1 and $(\mathrm{b}) \mathrm{H}=0.48 \mathrm{~m}$, Run 2
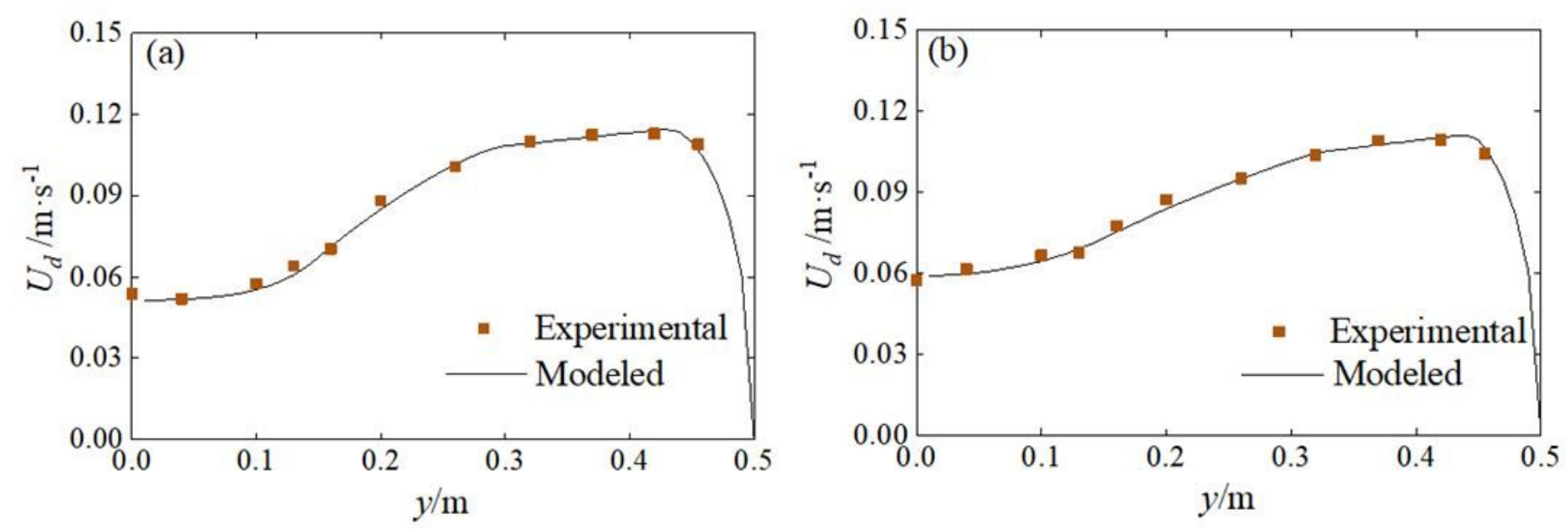

\section{Figure 6}

Transverse variation of depth-averaged streamwise velocity Ud for the symmetrical arrangement of FVls with narrow width $(b=0.3 \mathrm{~m})$ and two water depths of $(\mathrm{a}) \mathrm{H}=0.43 \mathrm{~m}$, Run 3 and $(\mathrm{b}) \mathrm{H}=0.48 \mathrm{~m}$, Run 4 

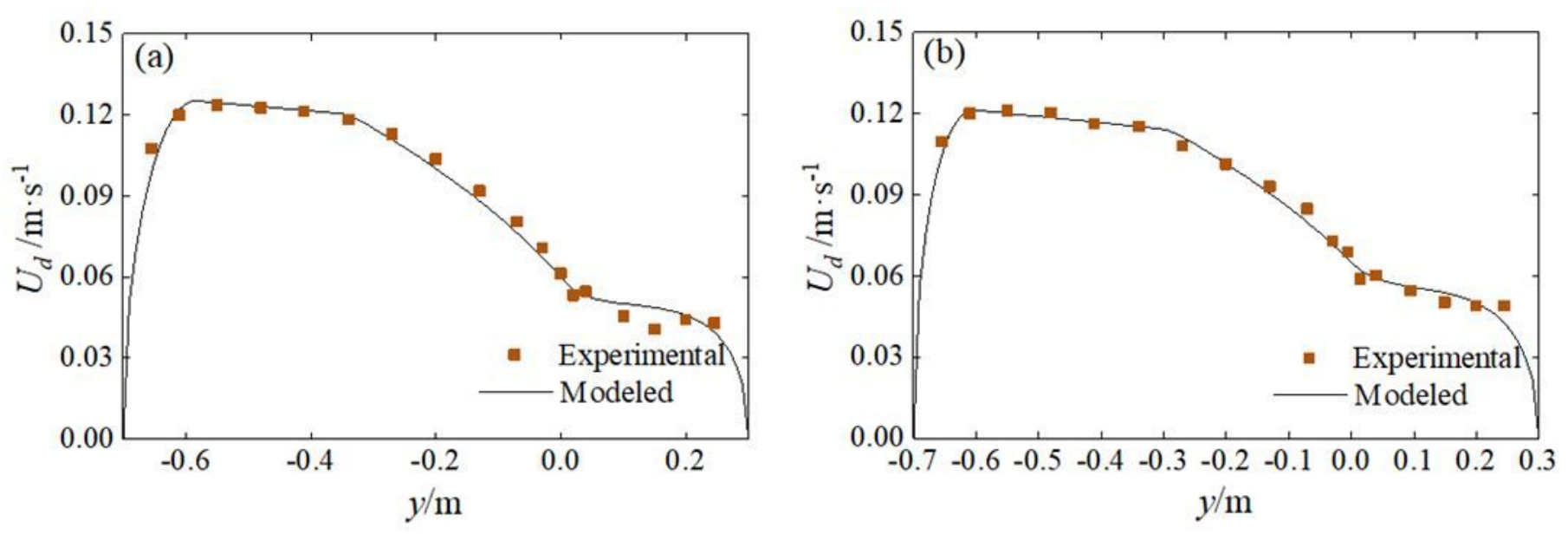

Figure 7

Transverse variation of depth-averaged streamwise velocity Ud for the asymmetrical arrangement of FVIs with two water depths of (a) $\mathrm{H}=0.43 \mathrm{~m}$, Run 5 and (b) $\mathrm{H}=0.48 \mathrm{~m}$, Run 6
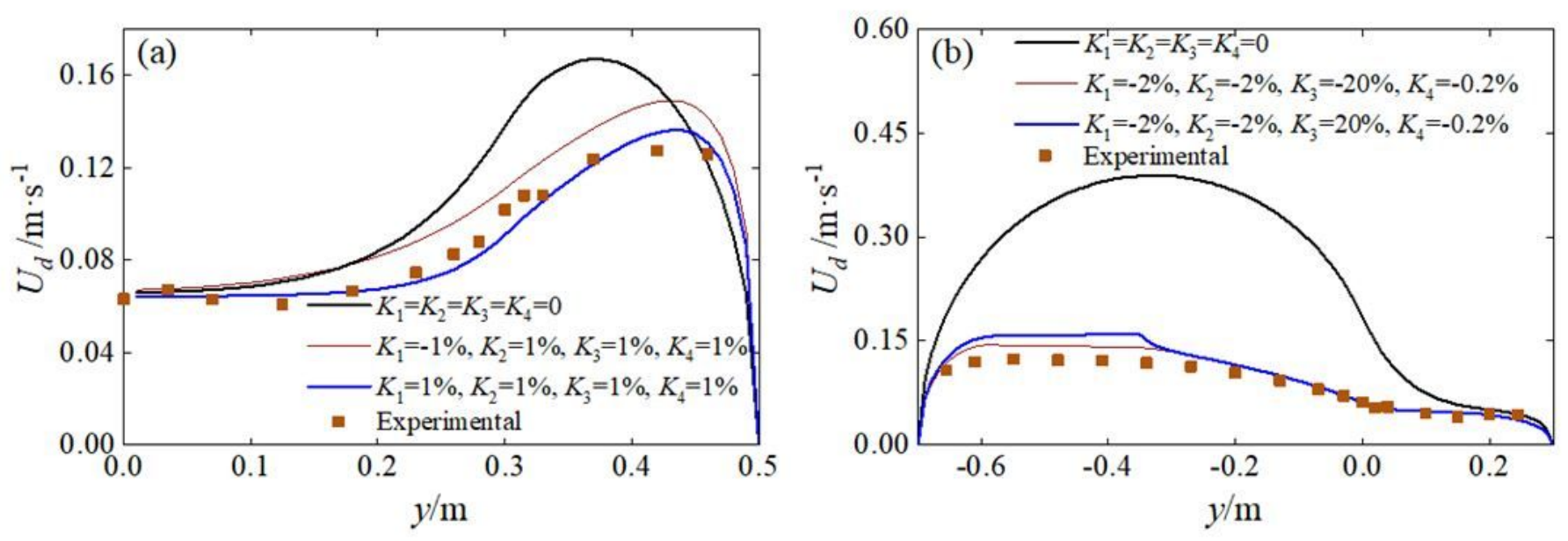

Figure 8

Influence of the secondary flow on the transverse variation of $\mathrm{Ud}$ for symmetrical and asymmetrical cases at a water depth of $\mathrm{H}=0.43 \mathrm{~m}$ : (a) Run 1 (b) Run 5 